\title{
Key Factors Affecting the Deformation and Failure of Surrounding Rock Masses in Large-Scale Underground Powerhouses
}

\author{
Meng Wang, ${ }^{1}$ Jia-wen Zhou $\mathbb{D}^{2},{ }^{2}$ An-chi Shi, ${ }^{3}$ Jin-qi Han, ${ }^{4}$ and Hai-bo Li $\mathbb{D}^{2}$ \\ ${ }^{1}$ State Key Laboratory of Hydraulics and Mountain River Engineering, Sichuan University, Chengdu 610065, China \\ ${ }^{2}$ College of Water Resource and Hydropower, Sichuan University, Chengdu 610065, China \\ ${ }^{3}$ PowerChina Huadong Engineering Co., Ltd., Hangzhou 311122, China \\ ${ }^{4}$ Sinohydro Bureau 7 Co., Ltd., Power Construction Corporation of China, Chengdu 610081, China \\ Correspondence should be addressed to Hai-bo Li; hbli@scu.edu.cn
}

Received 17 June 2020; Revised 5 September 2020; Accepted 25 September 2020; Published 12 October 2020

Academic Editor: Jianping Zuo

Copyright ( $\odot 2020$ Meng Wang et al. This is an open access article distributed under the Creative Commons Attribution License, which permits unrestricted use, distribution, and reproduction in any medium, provided the original work is properly cited.

\begin{abstract}
The stability of the surrounding rock masses of underground powerhouses is always emphasized during the construction period. With the general trends toward large-scale, complex geological conditions and the rapid construction progress of underground powerhouses, deformation and failure issues of the surrounding rock mass can emerge, putting the safety of construction and operation in jeopardy and causing enormous economic loss. To solve these problems, an understanding of the origins and key affecting factors is required. Based on domestic large-scale underground powerhouse cases in the past two decades, key factors affecting the deformation and failure of the surrounding rock mass are summarized in this paper. Among these factors, the two most fundamental factors are the rock mass properties and in situ stress, which impart tremendous impacts on surrounding rock mass stability in a number of cases. Excavation is a prerequisite of surrounding rock mass failure and support that is classified as part of the construction process and plays a pivotal role in preventing and arresting deformation and failure. Additionally, the layout and structure of the powerhouse are consequential. The interrelation and interaction of these factors are discussed at the end of this paper. The results can hopefully advance the understanding of the deformation and failure of surrounding rock masses and provide a reference for design and construction with respect to hydroelectric underground powerhouses.
\end{abstract}

\section{Introduction}

With the economic boom came the vigorous development of hydropower resources in China. Due to abundant hydropower resources, a number of hydropower stations have been constructed in southwest China, which has complex geological conditions and topography characterized by high mountains and deep valleys. Considering the constraints of both topography and engineering layout, most of the powerhouses here are arranged underground. For instance, most large-scale powerhouses built in the past two decades or to-be-built on major developed rivers (Figure 1 and Table 1) are underground [1-11]. Figure 2 shows the layout of the Houziyan underground powerhouse inside the mountain on the right bank of the Dadu River. Recent development of underground powerhouses in hydropower stations has witnessed a new trend of large-scale, complex geological conditions and fast construction progress. Under this circumstance, the deformation and failure of the rock mass surrounding underground powerhouses appear to be an inevitable and significant issue.

Rock mass, prior to excavation, remains in a state of complicated initial stress equilibrium. During excavation, the equilibrium state around the powerhouse is disturbed, and stress is redistributed to a certain area of the rock mass, which is usually called the surrounding rock mass. If the local redistributed stress exceeds the rock mass strength or if excessive deformation of the surrounding rock mass occurs, instability or failure of the rock mass will arise [12]. Many large-scale underground powerhouses for hydropower stations were constructed in the past two decades [13], and a number of surrounding rock mass deformation and failure 


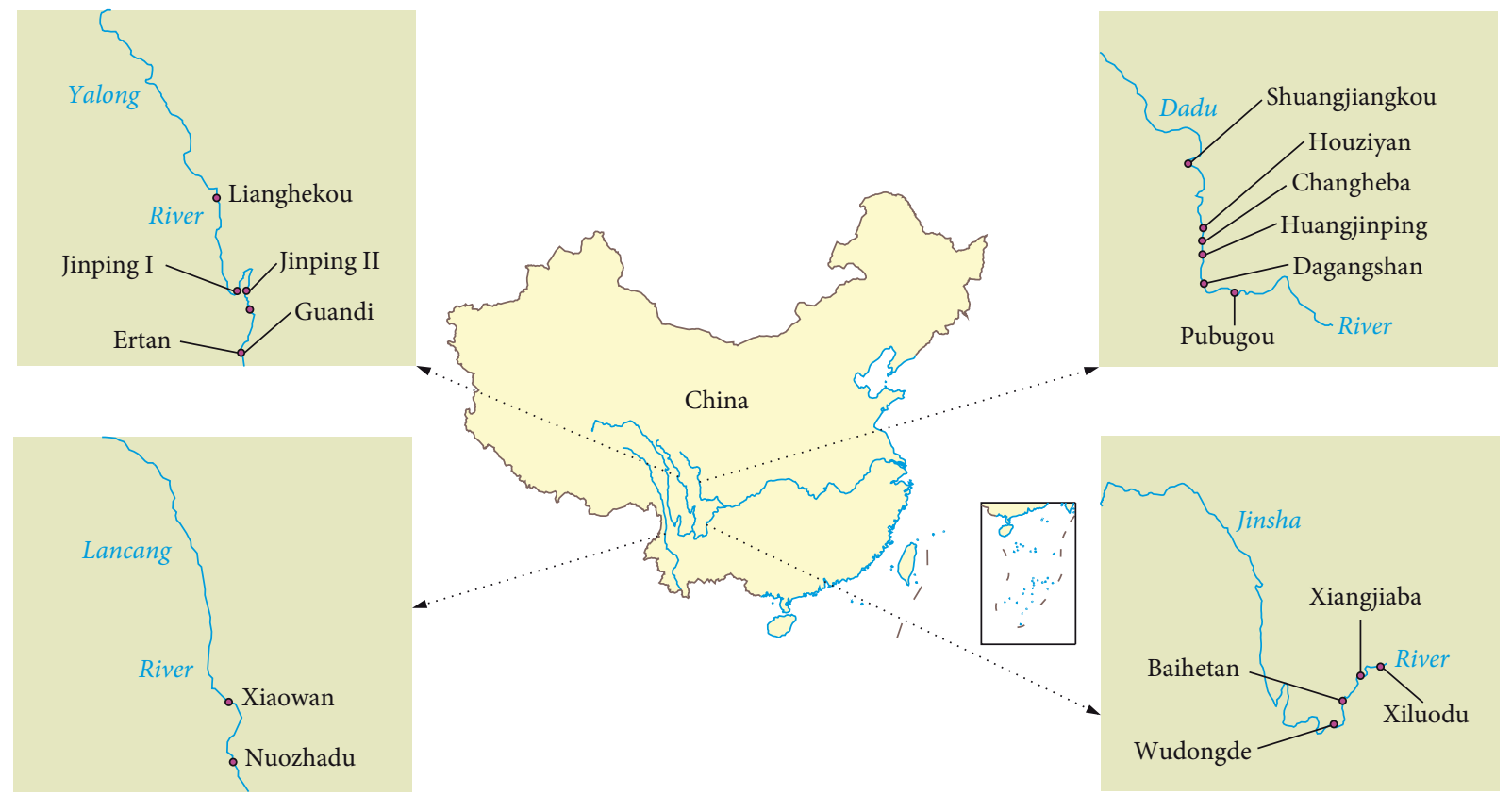

FIgURE 1: Hydropower stations with large-scale underground powerhouses in southwest China.

TABLe 1: Overview of large-scale underground powerhouses in southwest China [1-11].

\begin{tabular}{|c|c|c|c|c|}
\hline Project name & Basin & $\begin{array}{l}\text { Dimensions of the main powerhouse } \\
\left(\text { length } \times \text { width }^{\mathrm{a}} \times \text { height }(\mathrm{m})\right)\end{array}$ & $\begin{array}{l}\text { Lithology of the surrounding } \\
\text { rock mass }\end{array}$ & $\begin{array}{l}\text { Overburden depth } \\
(\mathrm{m})\end{array}$ \\
\hline $\begin{array}{l}\text { Wudongde (left } \\
\text { bank) }\end{array}$ & \multirow{4}{*}{ Jinsha River } & $333 \times 32.5 \times 89.3$ & $\begin{array}{c}\text { Limestone, marble, and } \\
\text { dolomite }\end{array}$ & $280-550$ \\
\hline Baihetan (left bank) & & $438 \times 34 \times 88.7$ & Basalt & $260-330$ \\
\hline Xiluodu (left bank) & & $400 \times 31.9 \times 71.5$ & Basalt & $340-480$ \\
\hline Xiangjiaba & & $255.4 \times 33.4 \times 85.5$ & Sandstone & $105-225$ \\
\hline Lianghekou & \multirow{5}{*}{$\begin{array}{l}\text { Yalong } \\
\text { River }\end{array}$} & $275.94 \times 28.4 \times 66.8$ & Sandstone & $410-560$ \\
\hline Jinping I & & $276.99 \times 28.9 \times 68.8$ & Marble & $160-420$ \\
\hline Jinping II & & $352.4 \times 28.3 \times 72.2$ & Marble & $231-327$ \\
\hline Guandi & & $243.4 \times 31.1 \times 76.8$ & Basalt & 420 \\
\hline Ertan & & $242.9 \times 30.7 \times 55.7$ & Orthoclase & $250-350$ \\
\hline Shuangjiangkou & \multirow{6}{*}{ Dadu River } & $198 \times 29.3 \times 63$ & Granite & $421-598$ \\
\hline Houziyan & & $219.5 \times 29.2 \times 68.7$ & Limestone & $400-660$ \\
\hline Changheba & & $228.8 \times 30.8 \times 73.35$ & Granite & $285-480$ \\
\hline Huangjinping & & $204.3 \times 28.8 \times 67.3$ & Granite and diorite & $<290$ \\
\hline Dagangshan & & $226.6 \times 30.8 \times 74.3$ & Granite & $390-530$ \\
\hline Pubugou & & $294.1 \times 30.7 \times 70.15$ & Granite & $200-360$ \\
\hline Xiaowan & Lancang & $298.1 \times 30.6 \times 86.43$ & Granite and gneiss & $380-480$ \\
\hline Nuozhadu & River & $418 \times 29 \times 77.8$ & Granite & $184-220$ \\
\hline
\end{tabular}

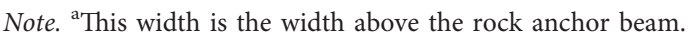

problems arose (Table 2). During the construction period of the Baihetan underground powerhouse, the shotcrete layer cracked, and local collapse occurred at the arch. During the first excavation step of the Dagangshan main powerhouse, a $\beta_{80}$ diabase dike at the arch collapsed with a volume of $3,000 \mathrm{~m}^{3}$ rock mass, which required a year and a half of disposal, resulting in a serious construction delay [14]. The surrounding rock mass deformation at the upstream sidewall of the Houziyan main powerhouse surged to $100 \mathrm{~mm}$ in July 2013. As a result, the project was shut down for more than two months, delaying construction and causing massive economic losses [15]. After the rock mass surrounding the Jinping I underground powerhouse was supported, deformation and failure of the supporting structure occurred as the load value of bolts and cables exceeded limits, and subsequent supplementary measures increased the monetary investment [16]. The deformation and failure of the rock mass surrounding an underground powerhouse not only lead to economic loss but also pose a threat to construction and operation safety. Moreover, it is more difficult and expensive to dispose of surrounding rock mass failures in large-scale powerhouses than in smaller or 


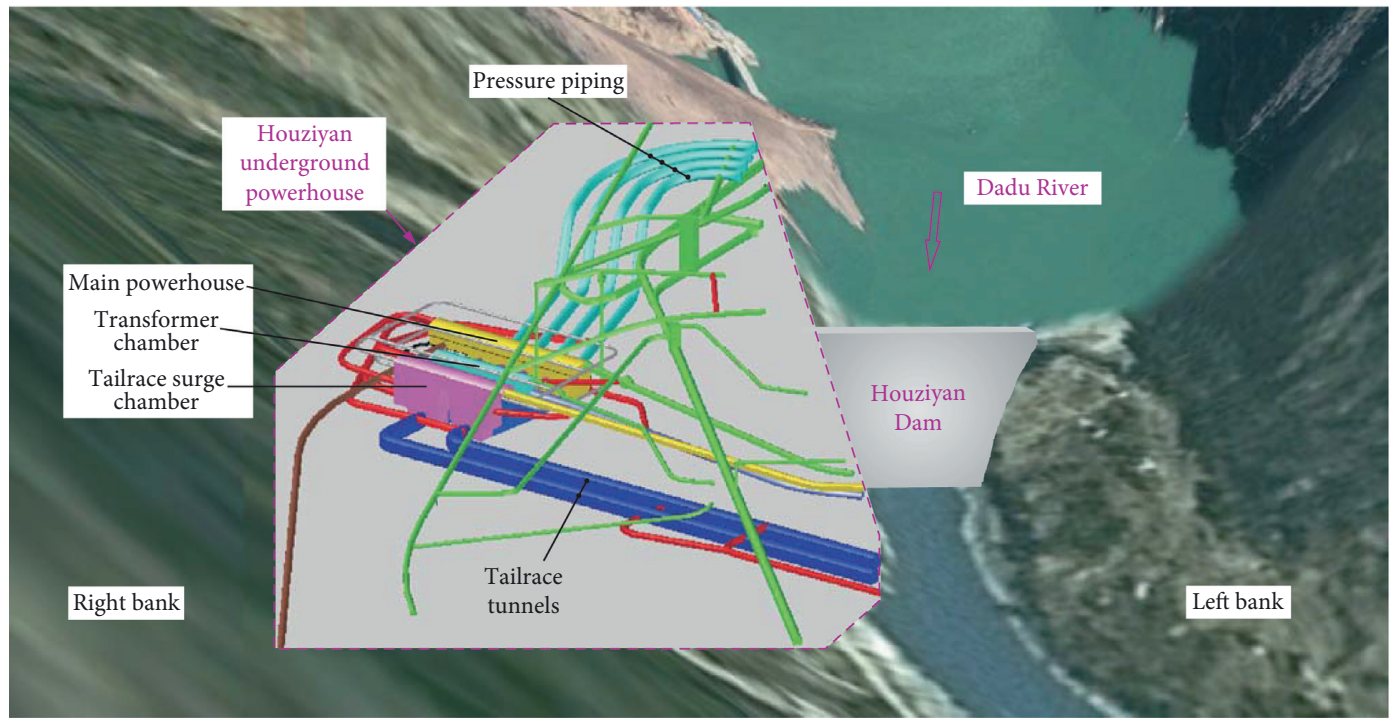

Figure 2: The Houziyan underground powerhouse inside the mountain on the right bank of the Dadu River.

TABle 2: Statistics of deformation and failure of the surrounding rock mass in some large-scale underground powerhouses during construction [1-11].

\begin{tabular}{|c|c|}
\hline Project name & Deformation and failure issues \\
\hline Baihetan & Spalling and large deformation of the surrounding rock mass, collapse, and shotcrete layer cracks \\
\hline Dagangshan & Dike collapse at the arch \\
\hline Ertan & Rockburst, peeling off of the surrounding rock mass and circumferential cracks in the omnibus bar cave \\
\hline Houziyan & $\begin{array}{c}\text { Splitting, slabbing, and large deformation of the surrounding rock mass, bolt head caving in, ballooning, and cracking of the } \\
\text { shotcrete layer }\end{array}$ \\
\hline Jinp & Spalling, splitting, bellying, and large deformation of the surrounding rock mass and shotcrete layer cracks \\
\hline Jinping II & Rockburst and spalling \\
\hline Laxiwa & Unstable block at the arch and circumferential cracks in the omnibus bar cave \\
\hline Longtan & Bedding toppling deformation of the surrounding rock mass and bolt fracture \\
\hline Pubugou & Rockburst and cracks at the rock anchor beam \\
\hline Three Gorges & Tensile fracture and shear deformation of blocks \\
\hline Xiaowan & Unstable blocks and cracks on the sidewall \\
\hline Xiluodu & Potential sliding blocks \\
\hline
\end{tabular}

single-cavern spaces. It is of significance, therefore, to study the deformation and failure of the surrounding rock mass as well as its prevention and control for large-scale underground powerhouses, which can help settle practical engineering issues and assemble pertinent experience, provide technical support for further hydropower development, and give potential reference to large-scale underground engineering in other industries, such as the energy industry.

To research the deformation and failure of the surrounding rock mass, its key affecting factors should be determined above all else. The preliminary design of an underground powerhouse involves scoping analysis and comprehensive assessment of these factors to avoid instability and failure of the surrounding rock mass [17]. In regard to failure mitigation, factors are studied to reveal the failure pattern and mechanism, which are quite useful for designing or optimizing countermeasures. Hence, it is viewed as a fundamental part to analyze affecting factors, and the key to ensuring surrounding rock mass stability is to master pivotal factors. Furthermore, there are a myriad of factors to consider, such as the diversity and characteristics of failure patterns. Previous studies were done on a case-bycase basis and investigated the failure phenomenon, including the triggers and mechanism of stability problems, in a single project rather than exploring the universalities and contrasting individualities among multiple engineering projects. Within the general trend of large-scale, complex geological conditions and rapid construction progress emerging in rapid domestic development of hydroelectric underground powerhouses in the past two decades, some affecting factors were universal, while their effects showed some differences. As a consequence, the analysis of factors should be summarized at a macrolevel of multiple engineering cases rather considering a single case; only in this way will universal results applicable to similar projects be gained. Based on domestic underground powerhouse cases in the past two decades and combining the work of predecessors, this paper summarizes key factors affecting the deformation and failure of the surrounding rock mass with a goal of advancing the understanding of surrounding rock 
mass failure in hydroelectric underground powerhouse projects.

\section{Powerhouse Layout and Structure}

The layout and structure of underground powerhouses, as well as in situ stresses, determine the basic pattern of the redistributed stress field in the surrounding rock mass after excavation, and the redistributed stress is the determinant of surrounding rock mass stability [18]. Among properties of the powerhouse layout, the most important are location, direction, and geometry. Additionally, for powerhouse structures, the intersection of caverns is an important factor. Preliminary powerhouse design involves scrutiny of these properties to see if design requirements can be met for the purpose of designing a stable powerhouse with minimal failure possibility.

2.1. Location and Direction. The location of the underground powerhouse is one of the key factors affecting surrounding rock mass stability within the construction and operation periods. It is universally known the powerhouse should be located in favorable geology. However, the geological environment is often quite complex, and structures adverse to stability are likely to be encountered including faults, weak interlayers, and fracture zones, which increase the failure risk in the surrounding rock mass. Therefore, these structures should be avoided as far as possible. If they are unavoidable, the powerhouse location and direction should be selected to minimize undesirable effects. In addition, the surrounding rock mass property is important, and poor rock mass quality is unfavorable for underground excavation. Selecting a proper location for the powerhouse, therefore, is of great importance to surrounding rock mass stability. Generally, underground powerhouses should be located, in terms of topography, in massive, intact, and stable mountains. The overlying and lateral overlying rock mass should be hard and intact and have appropriate thickness. Regarding geology, regional faults, active faults, and large karst caves should be avoided. Tunnels belonging to the powerhouse system should be located in areas characterized by favorable geological structure and intact and stable rock mass. In the presence of a large fracture structure, adverse structural zone, or weak zone, tunnel design should be assessed according to the influence extent of adverse structures on surrounding rock mass stability together with other factors including construction, operation, and investment.

In addition to the location, the powerhouse axis direction affects the surrounding rock mass stability in two ways: the relationship between the axis and the direction of in situ stress and the relative position relationship between the selected axis and adverse geology. In the presence of adverse geological structures, the angle between the powerhouse axis and the strike of the fault and major joints should be large to reduce the negative impact of these structures on surrounding rock mass stability. For the diversion tunnel, the tunnel axis should also have a large intersection with the altitude of rock formation and the strike of the tectonic fracture zone $[18,19]$. Under high in situ stress, the angle between the powerhouse axis and the direction of the maximum principal stress should be small [20]. This consideration is important because if this angle is large, the stress concentration around the powerhouse is more serious after excavation and stress redistribution, which is disadvantageous to surrounding rock mass stability. And it is advantageous if the powerhouse axis is parallel or intersects at a small angle with the direction of the maximum principal stress because the stress concentration can be mitigated. For instance, the angle between the axis of the Baihetan left bank underground powerhouse and the direction of the maximum principal stress is about $50^{\circ} \sim 70^{\circ}$, and the maximum principal stress is 19 23 MPa (Figure 3(a)). After excavation, stress concentrated at the upstream side of the arch, which brought about some stress-dominated failures including spalling and cracking of the surrounding rock mass and shotcrete layer, as shown in Figure 3(b).

As a result of various relationships between the powerhouse axis and the direction of in situ stress, the redistributed stress state around the powerhouse changes, impacting the surrounding rock mass stability to varying degrees. Numerical calculation done by Zhang et al. [21] on powerhouse excavation under various directions of in situ stress indicated that the redistributed horizontal maximum principal stress $\sigma_{\max }$ and stress differential $\sigma_{\max }-\sigma_{\mathrm{z}}$ went up as the angle between the powerhouse axis and the direction of the maximum principal stress increased. The increase of these two reflected an increasing probability of spalling failure, which was detrimental to powerhouse stability. This calculation analysis process was based on the assumption that the initial maximum principal stress was horizontal. Nevertheless, under the condition of vertical gravity stress larger than horizontal tectonic stress, the conclusion may be different. Li et al. [22] found that, in the stress field dominated by tectonic stress, the maximum tangential stress peaked when $\alpha_{1}$ was approximately $90^{\circ}$ and decreased when $\alpha_{1}$ was small, which was in accordance with the general rule mentioned above. For the stress field dominated by gravity stress, however, the conclusion was different. For instance, at approximately $\alpha_{1}=0^{\circ}$, the maximum tangential stress in the rock mass surrounding the Shiziping underground powerhouse reached its minimum, and the maximum tangential stress peaked when $\alpha_{1}$ was $156^{\circ}$ instead of $90^{\circ}$. The effect of the powerhouse axis on surrounding rock mass stability is related to the actual in situ stress state, and the differences in effects clearly emerge between the stress field dominated by gravity stress and tectonic stress. Accordingly, comprehensive assessment on multiple factors, including in situ stress as well as geological conditions and project layout rather than merely depending on the direction of the maximum principal stress, is necessary for determining the powerhouse axis. Specific issues need concrete analysis, and specifications and experiences should be incorporated.

Essentially, the selection of the powerhouse location and direction indirectly alters the impacts of in situ stress and rock mass properties on surrounding rock mass stability, and different locations and directions play a role of enlarging 


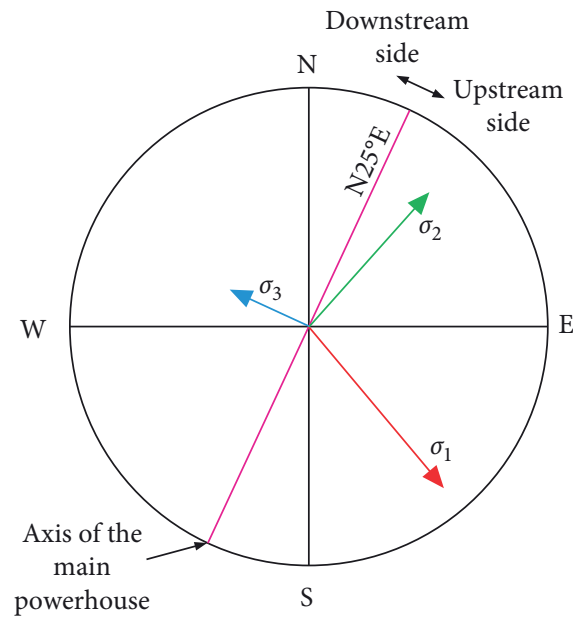

(a)

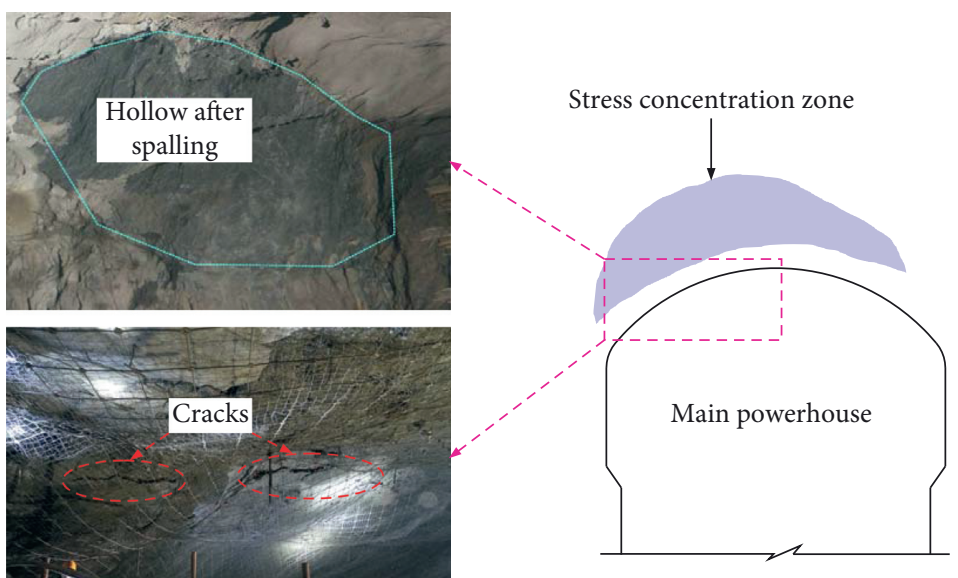

(b)

Figure 3: The stress-dominated failures in the Baihetan left bank underground powerhouse: (a) the correlation between the principal stresses and the powerhouse axis; (b) a hollow after spalling and shotcrete layer cracks at the upstream side of the arch.

or moderating impacts of these two factors. Reasonable and scientific location and direction of the powerhouse can avert or mitigate the deformation and failure of the surrounding rock mass to some extent, ensuring the construction and operation safety of the project.

2.2. Powerhouse Geometry. The geometry of underground powerhouses, including the shape and size of the section and the spacing between caverns, can make a difference to surrounding rock mass stability [23]. An arch shape with straight sidewalls is widely used for the section of domestic underground powerhouses. The shape presented in Figure 4(a), showing the three main caverns of the Baihetan underground powerhouse, is the most prevalent section shape of domestic powerhouses at present.

Diverse section shapes have different effects on surrounding rock mass stability. The section of the tunnel belonging to the powerhouse system usually adopts an arch shape with straight sidewalls or a horseshoe shape. Differences exist between these two shapes; the former is prone to tensile stress in certain situations as a result of barely curved sidewalls and floors, while the latter is not because its sidewall and floor have a large radius. For the powerhouse section shown in Figure 4(a), a stress concentration is likely to occur near the rock anchor beam on account of the protrusion there, and cracks would initiate if there were unfavorable local conditions, such as a weak structural surface. A horseshoe-shaped section, as is demonstrated in Figure 4(b), is employed in the Imaichi underground power station and has advantages in alleviating stress concentrations. Powerhouses with this section shape have smaller displacements and loosened zones in the surrounding rock mass [24]. Obviously, an optimal powerhouse section shape can improve the redistributed stress field and make full use of the self-bearing capacity of the surrounding rock mass, minimizing the damage and failure of the surrounding rock mass and contributing to long-term powerhouse stability. Hence, shape optimization of the powerhouse section is quite necessary in view of the undesirable conditions including high in situ stress and complex geological structure [25].

Apart from the section shape, section size can also influence surrounding rock mass stability. The excavation of the large-scale underground powerhouse, compared with a small chamber, causes longer and wider range of stress adjustment, which has undoubtedly bigger influence on the surrounding rock mass. Under the same geological condition, the stress adjustment caused by the excavation of the small chamber tends to be stable more quickly, while the deformation and damage of the rock mass surrounding a large underground powerhouse may develop continuously with the excavation process, and eventually, instability occurs. Thus, the support design of a large underground powerhouse is more complex than that of a small chamber, and safety monitoring for the surrounding rock mass is more demanding. Meanwhile, as the size of the powerhouse, which includes length, span, and height, has increased recently, the possibility of encountering adverse geological structure also increases. For instance, the Jinping I underground powerhouse did not avoid the high in situ stress region, and the Baihetan left bank underground powerhouse encountered weak interlayer zone $\mathrm{C}_{2}$ and internal staggered zones $\mathrm{LS}_{3152}$ and $\mathrm{LS}_{3255} \sim \mathrm{LS}_{3257}$. These factors became potential hazards to surrounding rock mass stability during the powerhouse construction.

Powerhouse geometry also includes the spacing between caverns. If the spacing is too small, stress concentrations in rock pillars between powerhouses will be severe, and the resulting thin rock pillar is unstable, threatening the construction and operation safety of the powerhouse. Take the Ertan underground powerhouse for instance. The two most 


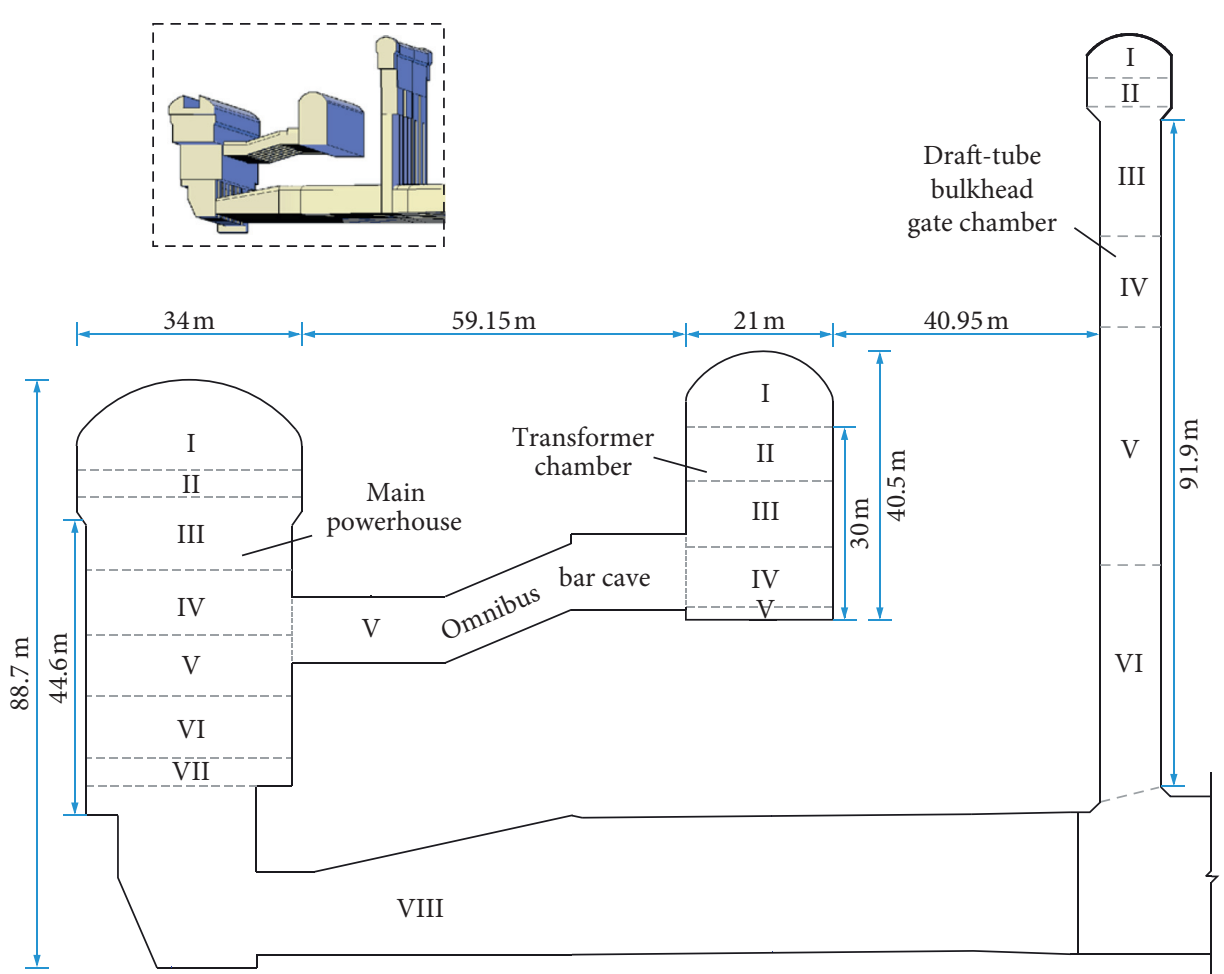

(a)

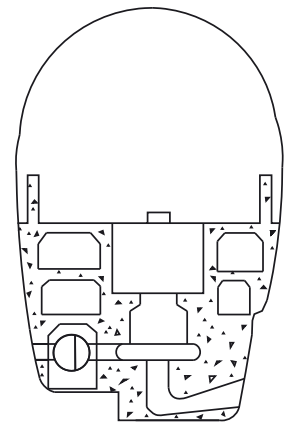

(b)

Figure 4: The section shape of (a) three main caverns of the Baihetan underground powerhouse and (b) the Imaichi underground power station.

severe rock bursts occurred when adjacent excavations connected on September 8, 1995, and April 30, 1996. Adjacent powerhouses are considered to pose amplification effects on in situ stress, and these effects will become greater when the middle rock pillar is thin. The rock pillar of the Ertan underground powerhouse, unfortunately, was the thinnest among all domestic powerhouses so far at only $35 \mathrm{~m}$ thick, which aggravated the stress concentrations and resulted in rock bursts [4]. For diversion tunnels, small spacing would increase the risk of seepage instability and hydraulic fracture within the operation period. However, in view of construction cost and general layout, the spacing between caverns should not be too large. As is stated in the specification [26], the thickness of a rock pillar between adjacent caverns should not be less than two times the cavern diameter or width. If smaller spacing is needed for the layout, the thickness can be reduced properly after discussion but should not be less than one time the cavern diameter or width. In specific engineering cases, the spacing between caverns should be determined via overall analysis on factors such as layout requirements, geological conditions, stress and deformation of the surrounding rock mass, section geometry, construction method, and operation conditions.

2.3. High Sidewall Effect. The recent economic boom and construction technique development have witnessed a surging scale of hydroelectric underground powerhouses in China. Whether the excavation volume or the height and span of the sections are considered, China ranks first in the world. Figure 5 shows the high sidewall in an underground powerhouse with a height beyond $30 \mathrm{~m}$. During the construction process of a large-scale underground powerhouse marked by a large span and high sidewall, the high sidewall effect appears quite prominent and serious. The high sidewall effect, a phenomenon involving large rebound deformation of the sidewall towards the free face and tensile crack growth in the surrounding rock mass, compromises the stability of the sidewall. Due to the impact of horizontal in situ stress, as the aspect ratio of the powerhouse section increases and, therefore, the sidewall becomes relatively higher, the probability of failure rises [27]. This effect would be more severe under high in situ stress as a consequence of strong unloading induced by excavation.

Through numerical implementation of the stratified excavation process of the Baihetan underground powerhouse, the evolution of the high sidewall effect can be presented clearly. The specific stratified excavation scheme, which covers eight excavation steps, is presented in Figure 4(a). The unit $2^{\#}$ section, owing to the more intact surrounding rock mass and the absence of a fault, can be selected as the observation section to analyze the distribution of displacement and the plastic zone within the excavation process. Figure 6 shows the horizontal displacement distribution of the surrounding rock mass at the unit $2^{\#}$ section in each excavation step.

As shown in Figure 6, the maximum horizontal displacement of the main powerhouse is approximately $20 \mathrm{~mm}$ and that of the transformer chamber is approximately $8 \mathrm{~mm}$ 


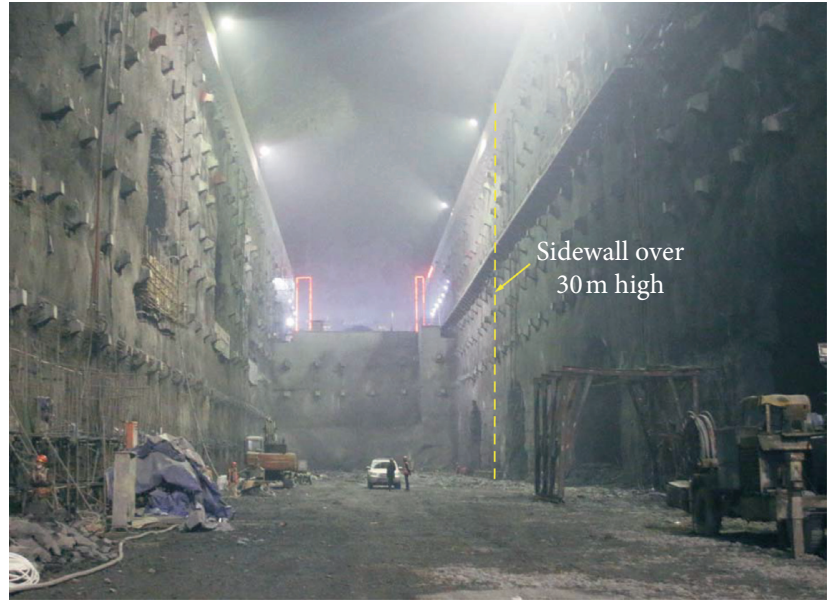

FIGURE 5: High sidewall at the underground powerhouse.
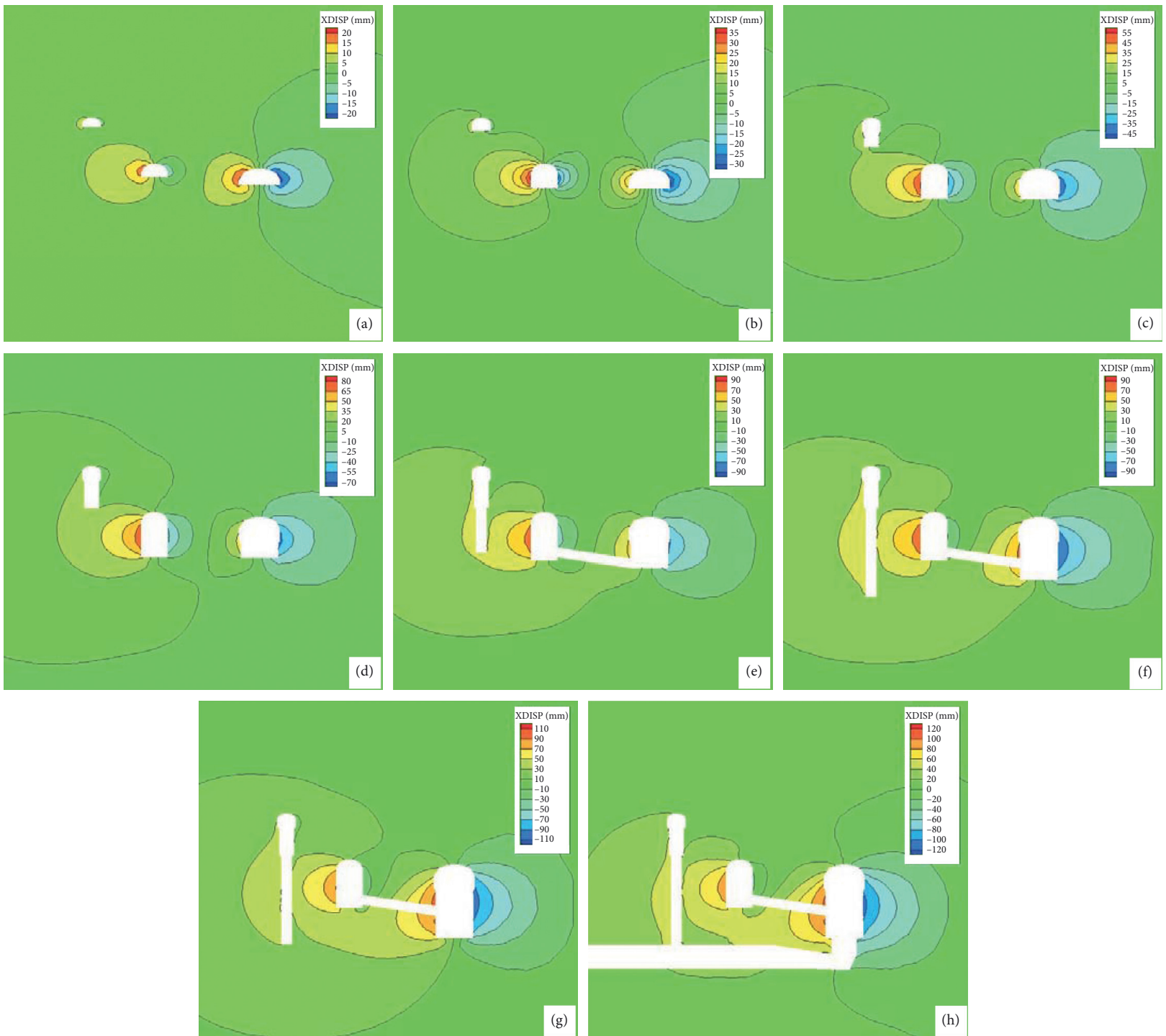

Figure 6: The horizontal displacement distribution of the surrounding rock mass at the unit $2^{\#}$ section at each excavation step of the Baihetan underground powerhouse. 
after the first excavation step. Within this step, the arch area of both the main powerhouse and the transformer chamber is excavated using a similar aspect ratio, but the main powerhouse has a larger displacement because its section size overshadows the transformer chambers. In subsequent excavation of the second, third, and fourth step, the high sidewall of the transformer chamber takes shape with an aspect ratio beyond 1, and the displacement of the sidewall keeps increasing. The sidewall displacement of the transformer chamber overshadows that of the main powerhouse. Since the high sidewall of the transformer chamber forms prior to the main powerhouse and the aspect ratio of the transformer chamber exceeds 1 while that of the main powerhouse remains under 1 , the transformer chamber witnesses more pronounced high sidewall effects, and the rebound deformation of its sidewall appears more serious. As excavation progresses, the displacement of both the main powerhouse and the transformer chamber keeps increasing. After the fifth step, the excavation of the transformer chamber is completed with sidewall displacement larger than that of the main powerhouse. The high sidewall of the main powerhouse takes shape, and sidewall displacement reaches the value of the transformer chamber with displacement at upstream and downstream sides approximately $90 \mathrm{~mm}$ after the sixth step. During later excavation processes, the aspect ratio of the main powerhouse keeps swelling, and the high sidewall effect becomes more apparent. The sidewall displacement of the main powerhouse eventually hits approximately $120 \mathrm{~mm}$ overshadowing that of the transformer chamber.

What can be learned from the comparison of displacement evolution between the main powerhouse and the transformer chamber is that the sidewall deformation is closely related to the change in the aspect ratio during excavation and that large deformation first arises at the cavern where the high sidewall forms earlier. Since the main powerhouse has a larger excavation size, its cumulative displacement overshadows that of the transformer chamber after excavation. Even though the high sidewall of the drafttube bulkhead gate chamber takes shape first, the change in sidewall displacement of this chamber is not as obvious as that of the other two caverns because of its small excavation size. Thus, large excavation size is also a precondition for the high sidewall effect, which usually occurs in large-scale underground powerhouses. Failures caused by the high sidewall effect, such as large sidewall deformation and cracks of the surrounding rock mass, are common in large underground powerhouses subjected to high in situ stress and strong unloading. In view of the impacts of the high sidewall effect on the surrounding rock mass stability, optimal excavation design and practical supporting measures should be taken [28].

2.4. Intersection of Caverns. The underground powerhouse of a hydropower station, such as the Baihetan underground powerhouse in Figure 7, features large-scale and complex structures, including the main powerhouse, transformer chamber, tail gate chamber, diversion tunnel, tailrace tunnel, omnibus bar cave, cable tunnel, access tunnel, and construction adit, and the whole cavern group is interconnected centering on three main caverns. Among the cavern group, the surrounding rock mass at the intersection of caverns, in the presence of multiple free faces, is more subject to instability and failure, for instance, the intersection between the main powerhouse and the omnibus bar cave shown in Figure $8(\mathrm{a})$, and the intersection of access tunnels is also shown. In effect, by reason of multiple free faces are generating severe unloading during excavation together with the interaction between adjacent excavations, the surrounding rock mass at the intersection of caverns has a higher likelihood of instability issues than other positions. With recent underground powerhouses growing in scale and complexity, this problem becomes acute.

This problem is quite prominent at the Baihetan main powerhouse. The downstream sidewall is linked with the transformer chamber via omnibus bar caves and, thus, the intersecting caverns take shape, which do not exist at the upstream sidewall. The surrounding rock mass displacement is measured via a multipoint extensometer, and the average displacement and displacement rate along the axial direction are obtained. The displacement rate, a value equal to displacement divided by monitoring time, is introduced to indicate the deformation rate of the surrounding rock mass in consideration of different starting times of measurement at different parts of the main powerhouse. For contrasting analysis, averages of three parts (arch area, rock anchor beam, and sidewall) on both sides (the upstream side and the downstream side) are demonstrated in Figure 8(b). As is reflected, the average of both displacement and displacement rate at the downstream side exceeds that on the upstream side with regard to these three parameters. The average displacement rate of the downstream sidewall exceeds that on the upstream side by $0.238 \mathrm{~mm} / \mathrm{d}$ to $0.125 \mathrm{~mm} / \mathrm{d}$, and the former is almost twice as much as the latter. The displacement rate of $0.238 \mathrm{~mm} / \mathrm{d}$ is quite large, which will bring about large deformation in the surrounding rock mass unless control actions are instigated, and large deformation has been observed at several points on the downstream sidewall. As to the arch area and rock anchor beam, the average on the downstream side is also larger than that on the upstream side, but the difference, as well as the magnitude of displacement rate, is clearly less than that of the sidewall.

The reasons for these observations are as follows. Omnibus bar caves connect the downstream sidewall to the transformer chamber; thus, the rock pillar between the main powerhouse and the transformer chamber has four free faces: front, back, left, and right, as shown in Figure 8(a). Excavation disturbance triggers stress redistribution and unloading of the surrounding rock mass towards the free face. Due to the presence of multiple free faces, the downstream rock pillar undergoes more intense unloading than the rock pillar on the upstream side. More intense unloading means greater sidewall deformation, and hence, the deformation rate of the downstream sidewall overshadows that on the upstream side. Eventually, the deformation magnitude of the downstream sidewall exceeds that 


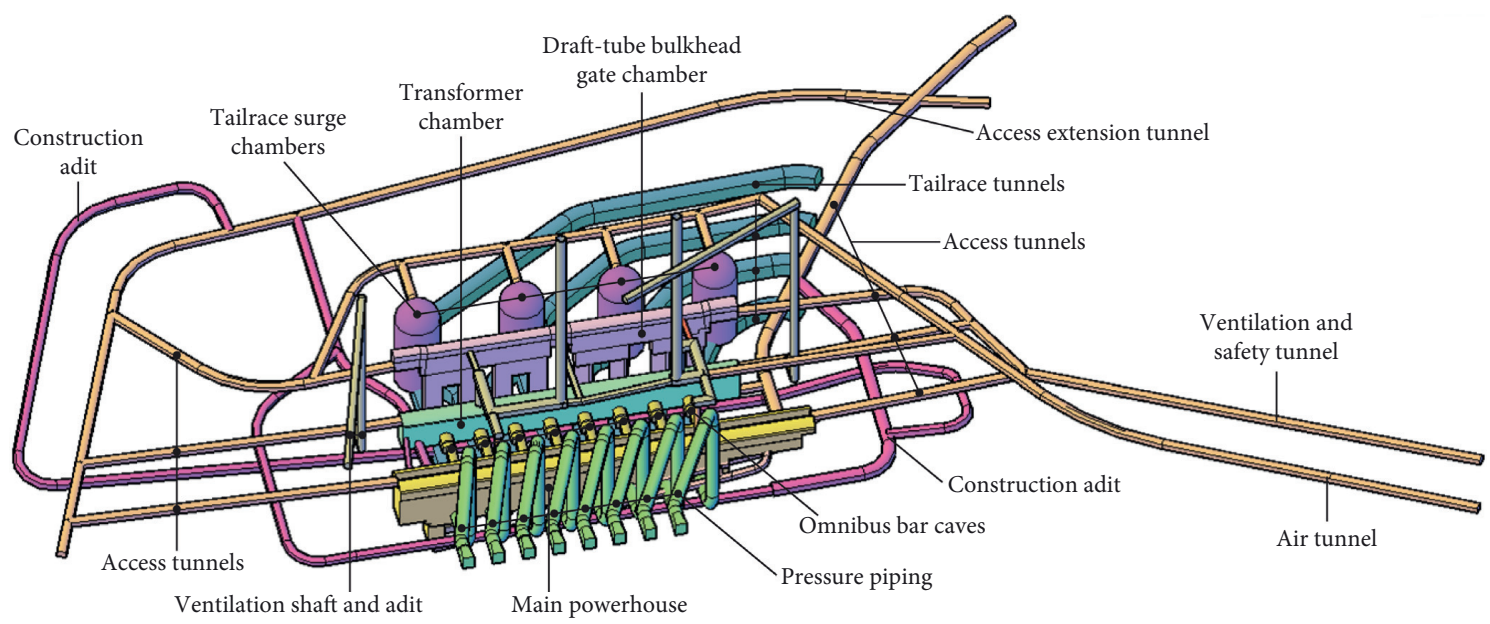

FIgURE 7: A three-dimensional representation of the Baihetan underground powerhouse.

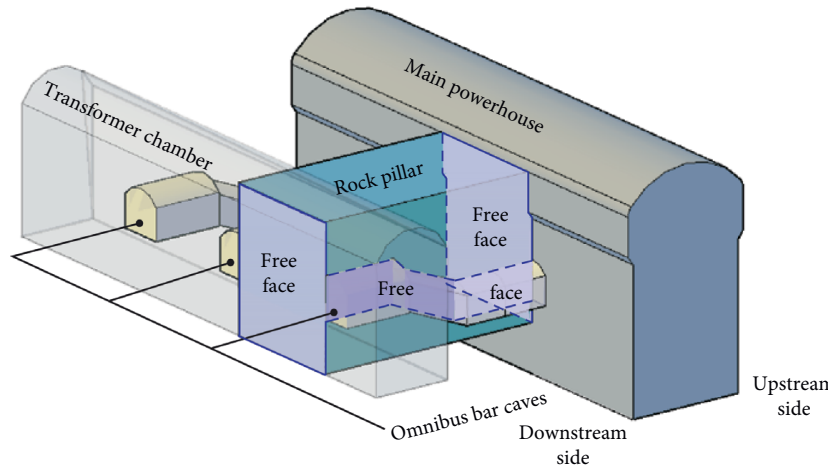

(a)

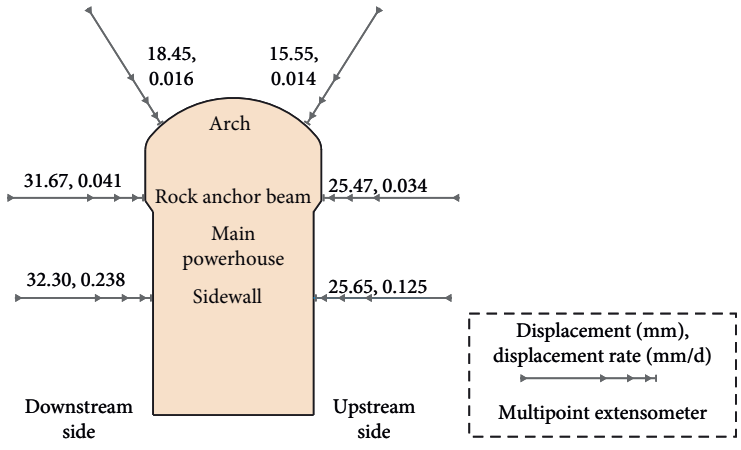

(b)

Figure 8: (a) The rock pillar between the main powerhouse and the transformer chamber with multiple free faces and (b) the average displacement and displacement rate of different parts of the main powerhouse.

on the upstream side as well as that of the arch area and rock anchor beam. Therefore, because of more intense unloading triggered by excavation disturbance, the surrounding rock mass at the intersection of caverns has a higher deformation rate and greater risk of large deformation, spoiling the stability of the underground powerhouse.

The downstream sidewall of the main powerhouse has larger deformation than the upstream side because the intersection has been a prevalent phenomenon, which also occurs in the other underground powerhouses [29]. In addition to the intersection of the main powerhouse and the omnibus bar cave, there are many intersections of caverns in the underground powerhouse, such as the intersection of the main powerhouse and the diversion tunnel, of the tailrace tunnel and the construction adit, or of access tunnels. Though sharing different sizes or numbers of intersecting caverns, these intersections may experience varying degrees of instability problems from the surrounding rock mass, for example, large deformation, circumferential cracks, or local collapse, thus posing a threat to the safety of construction and operation. For intersecting caverns, there are also many factors influencing the deformation and failure of the surrounding rock mass, such as the crossing angle between caverns and the difference in the size of the cavern when they are in the same rock layer or different rock layers. The effect and mechanism of these factors need to be further studied in the subsequent work combining engineering cases. Overall, in regard to the surrounding rock mass stability, the intersection of caverns is a factor of nonnegligible importance as well.

\section{In Situ Stress}

Of all the factors that affect the deformation and failure of the rock mass surrounding an underground powerhouse, the two most fundamental are rock mass properties and in situ stress. Once the powerhouse site is determined, the geological conditions and in situ stress remain unchangeable, the impacts of which can only be altered indirectly by adjusting other pertinent factors. In situ stress is the fundamental force leading to the deformation and failure of the surrounding rock mass. Excavation disturbance results in stress adjustment in the surrounding rock mass, generating a redistributed stress field. If the redistributed stress exceeds the ultimate strength of the rock mass, the surrounding rock mass will be subject to failure. 
In situ stress is a crucial factor for surrounding rock mass stability. Via its magnitude, direction, and distribution characteristics, in situ stress influences properties of the redistributed stress field, thereby affecting the surrounding rock mass stability. The first factor is the magnitude of in situ stress. It is well known that high in situ stress is the trigger of some failure phenomena, such as rock bursts, spalling, core disking, borehole or tunnel breakout, and shear rupture [30-32], putting the construction and operation safety of underground engineering in jeopardy. Recently, hydropower resources have been developed energetically in southwest China; this region features high in situ stress as a result of tectonic movement, which triggers many failure phenomena in the surrounding rock mass and poses a challenge to project construction. High in situ stress has consequently become a matter of great concern and vital importance. With respect to the definition of high in situ stress, there are many methods at home and abroad, which can be divided into three types. The first type of high in situ stress is based on the magnitude of in situ stress. The second, considering the magnitude of in situ stress and the uniaxial compressive strength of the rock, uses the strength-stress ratio as the criterion. The last one takes the combination of in situ stress magnitude and strength-stress ratio into account [4].

According to the in situ stress rating scheme in the technical code for the power industry [19], which belongs to the third definition mentioned above, together with the collected engineering data [33], in situ stress rating results from fourteen domestic large-scale underground powerhouses are presented in Figure 9. As shown in Figure 9, high in situ stress is a prevalent issue among these powerhouses. For instance, the Houziyan underground powerhouse exhibited high in situ stress, the Baihetan underground powerhouse showed medium-high in situ stress, and a minority even demonstrated high-extremely high in situ stress, as seen in the Jinping I underground powerhouse. These three underground powerhouses suffered failures induced by high in situ stress during construction. Spalling, splitting, bellying, and deep fracture of the surrounding rock mass, large deformation of the sidewall, and cracking of the shotcrete layer occurred in the Jinping I underground powerhouse. Splitting, slabbing, and large unloading deformation of the surrounding rock mass, bolt head caving in, and ballooning and cracking of the shotcrete layer happened in the Houziyan underground powerhouse. The construction of the Baihetan underground powerhouse encountered rock burst, spalling, and large deformation of the surrounding rock mass, as well as shotcrete layer cracks. High in situ stress and low rock mass strength-stress ratio, which are common in the underground powerhouse in southwest China, have caused many stress-dominated failures of the surrounding rock mass and posed severe challenges to the construction of domestic large underground powerhouses.

Three projects in high-extremely high in situ stress areas, high in situ stress areas, and medium-high in situ stress areas, the Jinping I underground powerhouse, the Houziyan underground powerhouse, and the Baihetan underground powerhouse, respectively, are selected, and the surrounding rock mass deformation of the main powerhouse is measured and statistically analyzed. Figure 10 presents different proportions of each deformation magnitude and the maximum deformation. According to Figure 10, the surrounding rock mass deformation of the three powerhouses is generally at a larger level. Specifically, although the deformation under $30 \mathrm{~mm}$ has the largest proportion at Jinping I, accounting for $80.3 \%$, the share of deformation beyond $50 \mathrm{~mm}$ exceeds $10 \%$. Houziyan has three types of deformation magnitude; Houziyan demonstrates the smallest quantitative differences, but overall, its deformation is the largest of three powerhouses, presenting the largest maximum deformation and the most deformation magnitude, beyond $30 \mathrm{~mm}$ and $50 \mathrm{~mm}$, compared to the other two powerhouses. For Baihetan, the distribution of each deformation magnitude is normal: the larger the deformation is, the smaller the proportion is. However, the deformation beyond $30 \mathrm{~mm}$ of Baihetan takes a share of $26.23 \%$, greater than that of Jinping I. Generalizing from these three cases, it can be seen that the surrounding rock deformation of the underground powerhouse with high in situ stress is also at a large level among similar powerhouses.

These three powerhouses are ranked according to the in situ stress rating results in Figure 9, and the order of ascending in situ stress is Baihetan, Houziyan, and Jinping I. However, the surrounding rock mass deformation of Houziyan is shown to be the largest of the three. From an in situ stress perspective, the surrounding rock mass at Houziyan is the most deformed, indicating that the major determinant of large deformation may not be the maximum principal stress measured in the powerhouse area or the strength-stress ratio obtained from calculation involving the maximum principal stress. Apart from high maximum principal stress, the second principal stress affecting the Houziyan underground powerhouse area is also high and has a direction subvertical to the axis of the main powerhouse, which plays a more significant role in the large deformation as well as other failures of the surrounding rock mass.

As mentioned in Section 2, the axis of the powerhouse is usually set to subparallel to the direction of the maximum principal stress in order to ease the detrimental effects of in situ stress on powerhouse stability. This layout gives priority to the maximum principal stress; however, it neglects the impacts of the second principal stress, particularly in cases under high second principal stress. The Houziyan underground powerhouse is a typical case where the high second principal stress makes bigger impact on surrounding rock mass failure. As shown in the stress measurement results of the Houziyan underground powerhouse area, the maximum principal stress was $21.53 \sim 36.43 \mathrm{MPa}$ and had a direction of almost parallel to the powerhouse axis, while the second principal stress was $12.06 \sim 29.08 \mathrm{MPa}$ and was subvertical to the powerhouse axis (Figure 11). The layout of the powerhouse axis intersecting with the direction of the maximum principal stress at a small angle brought the undesirable outcome that the axis was subvertical to the direction of the second principal stress. As results of numerical simulation show, when the value of the second principal stress increases, 


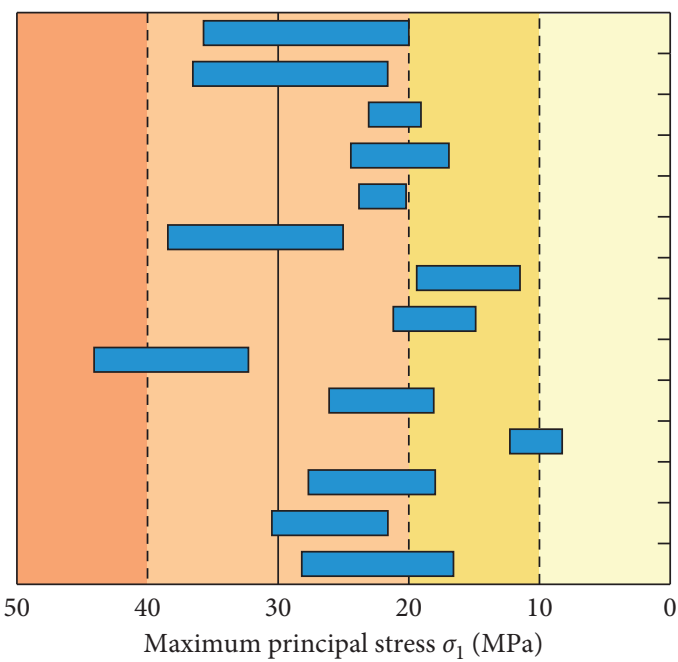

Extremely high High

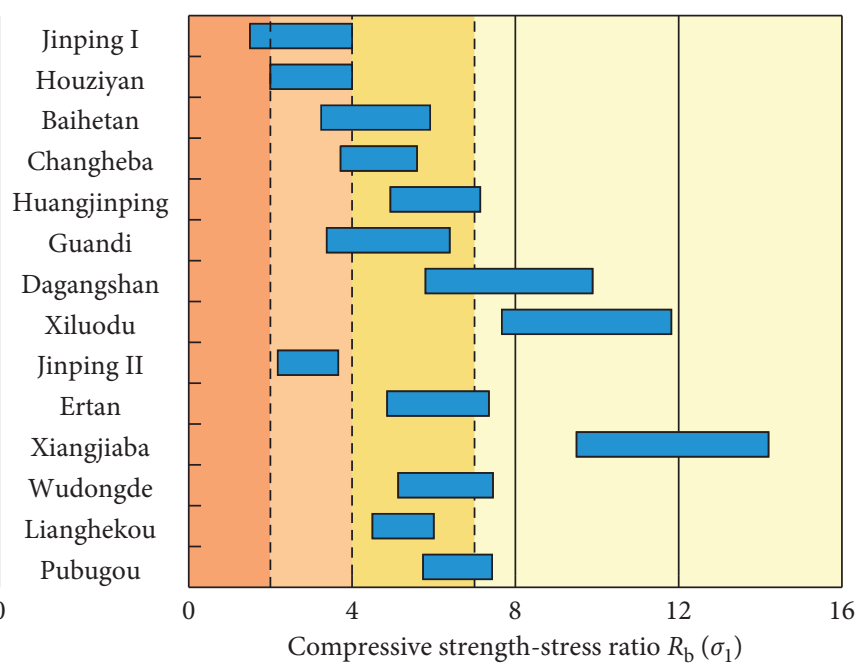

Medium

Low

FIGURE 9: In situ stress rating results of fourteen domestic large-scale underground powerhouses.

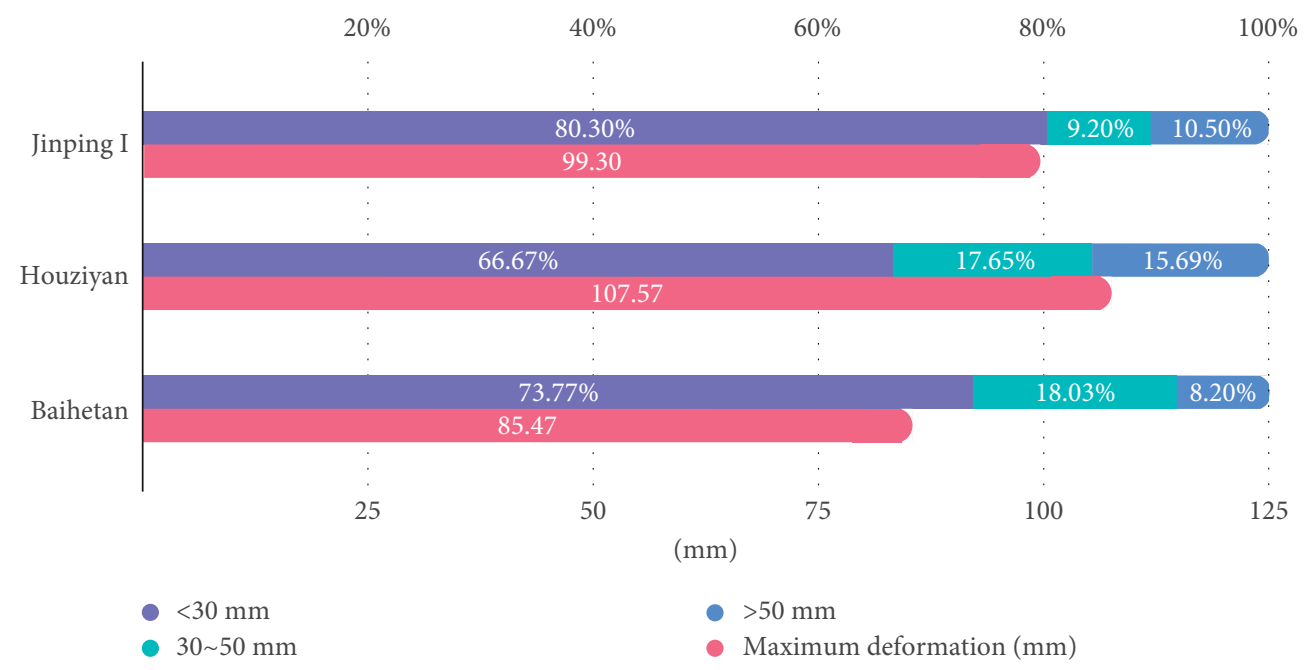

FIGURE 10: Statistical results of surrounding rock mass deformation for the three main powerhouses.

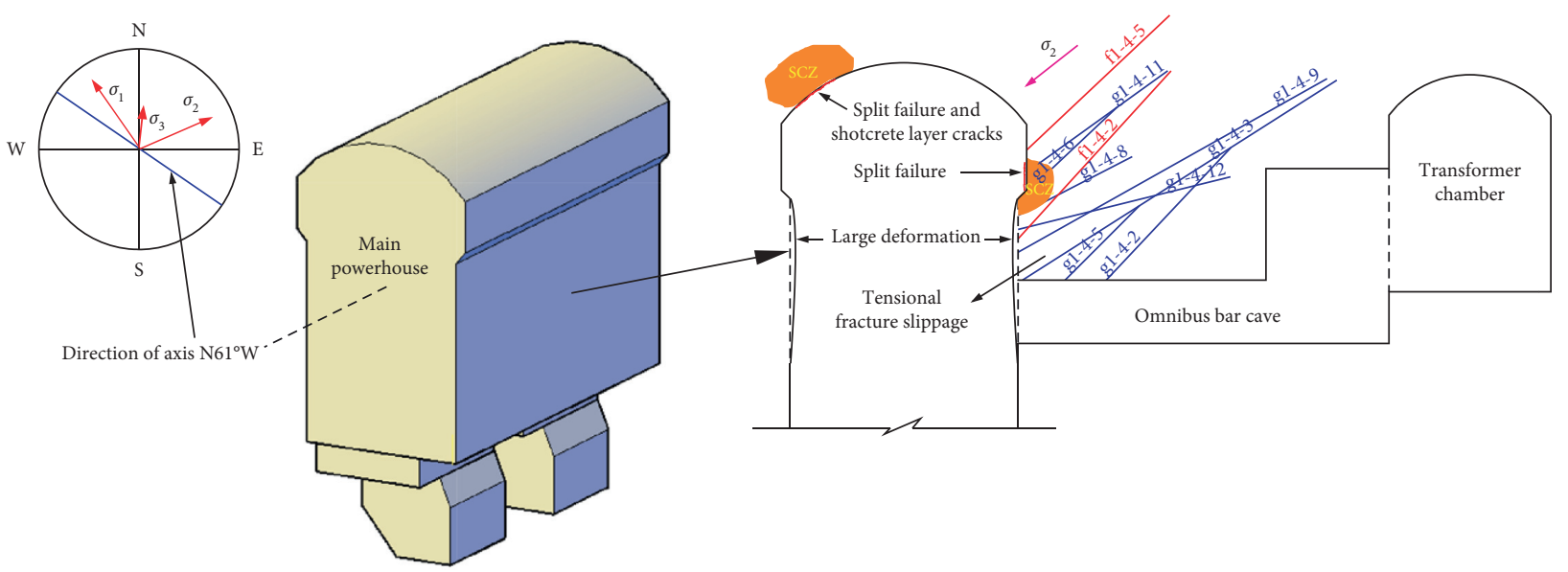

FIGURE 11: The relationship between the direction of principal stresses and the axis of the Houziyan main powerhouse and failures in the stress concentration zone (SCZ). 
the stress concentration at the upstream spandrel and downstream arch foot of the main powerhouse intensifies, and the horizontal deformation of the sidewall enlarges. When the value of the second principal stress remains constant, the horizontal deformation of the sidewall swells with the increase of the angle between the axis of the main powerhouse and the direction of the second principal stress. The high second principal stress subvertical to the powerhouse axis puts the surrounding rock mass under high confining pressure. During the excavation process, stress is unloaded in the direction of the second principal stress, and tangential stress is concentrated at the upstream spandrel and the downstream arch foot. Strong unloading led to large deformation of sidewalls, and stress concentration resulted in splitting of the surrounding rock mass and cracking of the shotcrete layer, as is shown in Figure 11 [34]. Moreover, results of field investigation showed stress-dominated failure accounted for more in surrounding rock mass failures, while rock mass property-dominated failure was relatively less, which indicated the significant role of high in situ stress on failures. Therefore, the high second principal stress with a direction subvertical to the powerhouse axis led to the aforesaid large deformation and failure of the surrounding rock mass in the Houziyan underground powerhouse.

Current in situ stress rating schemes, whether via the maximum principal stress solely, via strength-stress ratio solely, or via the combination of the two, are mainly based on the maximum principal stress. Cases under high second principal stress, such as the Houziyan underground powerhouse, may arise again in the future, to which current in situ stress rating schemes may not apply. Therefore, it is a question worth discussing whether the second principal stress should be taken into consideration in in situ stress rating schemes. In addition, the selection of the in situ stress value is also a topic worthy of further discussion. In the area of high mountain canyon topography, the distribution of in situ stress is uneven, and its magnitude may vary greatly at different locations within a project. Hence, the challenge of how to select a representative value of in situ stress is also important.

Not only can the value but also the direction of in situ stress can make a difference to the surrounding rock mass stability. As mentioned in Section 2, the relationship between the powerhouse axis and the direction of the maximum principal stress affects the property of the redistributed stress field, and a small intersection angle is conducive to the stability of the underground powerhouse. The axes of both the Houziyan underground powerhouse and the Baihetan underground powerhouse intersect with the direction of the principal stress at a large angle, which caused stress-dominated failures in these two powerhouses. Furthermore, diverse directions of in situ stress determine different failure modes. Emerging from the excavation process of the Jinping I underground powerhouse were two different failure modes, high tangential stress-induced failure and progressive failure, which mainly resulted from the difference in the in situ stress direction between two areas. Consequently, the surrounding rock mass in these two areas exhibited different deformation properties and the evolution law of EDZ [1].

\section{Rock Mass Properties}

In addition to in situ stress, rock mass property is another most fundamental factor affecting the deformation and failure of the rock mass surrounding the underground powerhouse. Rock mass properties cover many aspects such as physical, mechanical, hydrophilic, and structural, among which the most significant for surrounding rock mass stability are strength and structural properties.

4.1. Strength Property. The strength property of the rock mass, defined as the resistance of the rock mass to external damage, is vital to the surrounding rock mass stability. Powerhouse excavation causing stress adjustment: if the adjusted stress in the surrounding rock mass exceeds its ultimate strength, failure will occur. An underground powerhouse is always located inside the hard and intact rock mass, and this hard and intact rock mass usually remains stable after excavation, and it is conducive to the efficiency and safety of construction. Recent domestic large-scale underground powerhouses opt for rock mass with higher strength as much as possible, such as basalts with a uniaxial compressive strength of $155-179 \mathrm{MPa}$ in the Xiluodu underground powerhouse and $130 \sim 206 \mathrm{MPa}$ in the Guandi underground powerhouse [33]. If excavated in weak, fractured, and loose rock mass, the roof of the powerhouse is susceptible to collapse, and the sidewall and floor are prone to ballooning and extrusion. Under these circumstances, excavation and support should be simultaneous or the latter be conducted in advance, which would lead to long construction periods, high costs, and potential safety risks. A typical example of low-strength rocks is soft rock. Soft rock, one defined as a kind of rock with uniaxial compressive strength less than $25 \mathrm{MPa}$ by the ISRM, features low mechanical strength, large deformation, and difficulty in supporting, which cause many accidents in engineering construction $[35,36]$. For instance, soft-rock tunnels along the Guang-Gan Expressway suffered from many large deformation and collapse problems and incurred great risks during the construction process [37]. Regarding hydropower stations, the second and third excavation layers of the Shuibuya underground powerhouse, which is characterized by poor geological conditions, are in the soft-rock area. To ensure construction safety, only after the rock mass surrounding the sidewall is replaced with concrete could the subsequent excavation progress [38].

However, it is of little significance to consider rock mass strength alone, and what is generally considered is the relative magnitude between rock mass strength and in situ stress, which can be represented by strength-stress ratio. This is because the criterion for rock mass failure is that stress exceeds ultimate strength, and it is pointless to discuss rock mass strength without reference to the magnitude of in situ stress. Besides, in the presence of fissures, joints, bedding, faults, and other structural planes, the strength of the rock mass is determined by the strength of both rock and structural plane. Especially in the case where the rock mass slides along a structural plane, the strength of the structural 
plane plays a dominant role in rock mass stability. In actual engineering, therefore, the strength of the rock and structural plane should be comprehensively assessed in combination with the geological condition.

4.2. Structural Properties. Structural properties of the rock mass cover the shape, size, property, and composition relationship of structural planes and rocks. Structural plane affects the mechanical properties of the rock mass by making it discontinuous and anisotropic. In underground openings, structural planes such as faults, fissures, joints, and fracture zones have a great impact on surrounding rock mass stability. These adverse structural planes compromise the integrity and continuity of the rock mass, debase its strength and stability, and provide seepage channels for groundwater, which provide preconditions for the deformation and failure of the rock mass surrounding an underground powerhouse. During the unloading induced by excavation, stress concentration is apt to arise at the tip of the joint and crack, which makes cracks grow, develop, and aggregate and eventually cause unloading damage and large deformation of the surrounding rock mass. In the presence of a large fault or fracture zone, the rock mass is highly unstable, and collapse or caving in is very likely to occur during the underground excavation. The degree of joint development and the strike and dip of the joint can make a difference in the failure pattern of the surrounding rock mass. If joints develop less and the rock mass is relatively intact, failure usually shows as rock bursts, spalling, splitting, or slabbing depending on the magnitude of in situ stress. For a set of parallel joints in the rock mass, the major failure pattern is shear deformation failure along the joint surface. When two sets of joints interlace at a large angle, collapse may take place. Additionally, joint persistence is also an important parameter affecting rock mass strength [39].

Cases of surrounding rock mass failure triggered by structural planes abound. There are many structural planes in the rock mass surrounding the downstream sidewall of the Houziyan underground powerhouse, such as compression-crushed zones g1-4-2 g1-4-12 and faults f1-4-2 and f1-4-5. The surrounding rock mass of the downstream sidewall is cut by multiple, interlaced, steep structural planes. During the excavation process, stress is relieved approximately in the direction of the second principal stress, leading to tensile stress concentrations at the downstream rock bench. Under the action of tensile stress, intermittent fractures and block slipping occurred [34], as is reflected in Figure 11. Affected by tectonic movement, the rock mass at the Jinping I underground powerhouse area has many structural planes which caused deformation and failure of the surrounding rock mass. Geological investigation reveals three large-scale faults, $F_{13}, F_{14}$, and $F_{18}$, and many small faults and a lamprophyre dike $(X)$ including many joints and cataclastic rock mass. Under the cutting action of these structural planes, unstable blocks were formed in this area. Two sections, $\mathrm{K} 0+31.7 \mathrm{~m}$ and $\mathrm{K} 0+126.8 \mathrm{~m}$, are selected for comparative analysis of measured surrounding rock mass deformation. Section $\mathrm{K} 0+126.8 \mathrm{~m}$ is crossed by $F_{14}, F_{18}$, and $X$, as shown in Figure 12(a). Thirteen measured points are selected in each of the two sections (Figure 12(a)), and the deformation of points is presented in Figure 12(b). As is reflected, the surrounding rock mass deformation in section $\mathrm{K} 0+126.8 \mathrm{~m}$ with faults and $X$ is generally larger than that in section $\mathrm{K} 0+31.7 \mathrm{~m}$ with relatively intact surrounding rock mass, especially at the downstream sidewall of the transformer chamber. In the presence of large-scale faults and $X$, the quality of the surrounding rock mass in section $\mathrm{K} 0+126.8 \mathrm{~m}$ is poor, and thus, the deformation is larger, the maximum even reaching $236.7 \mathrm{~mm}$ in September 2010 (point 12 on the downstream sidewall of the transformer chamber) [1]. In addition, $F_{18}$ and $X$ also resulted in rock fall during the excavation of the auxiliary powerhouse, and shotcrete layer cracks on the downstream sidewall in section K0 + 197 0 + $204 \mathrm{~m}$.

There is a weak interlayer zone $\mathrm{C}_{2}$ in the Baihetan left bank underground powerhouse area (Figure 13(a)). $C_{2}$ is $10 \sim 60 \mathrm{~cm}$ thick and appears at the north endwall of the installation chamber and the sidewall of the main powerhouse. It is mixed with mud and debris and is susceptible to softening when wet. Even if deep antishear tunnel and shallow antishear adit as well as reinforcing cables were employed, shear deformation along $\mathrm{C}_{2}$ still occurred on the downstream sidewall during excavation. During the excavation of layer $\mathrm{VII}_{2}$ of the powerhouse, $\mathrm{C}_{2}$ was exposed remarkably. In the meantime, the multipoint extensometers of the downstream sidewall along $C_{2}$ witnessed a displacement rise of $9.9 \sim 37.53 \mathrm{~mm}$, and shear deformation of $38.90 \mathrm{~mm}$ and $23.99 \mathrm{~mm}$ was measured by clinometers in $3^{\#}$ and $4^{\#}$ omnibus bar caves, as shown in Figure 13(b). Surrounding rock mass was cut by the combination of gently dipping $\mathrm{C}_{2}$, steep fissures, and columnar joints. As a result, some rocks fell along $\mathrm{C}_{2}$ during excavation (Figure $13(\mathrm{c})$ ). The shotcrete layer of the downstream sidewall cracked from stake $\mathrm{ZC} 0+134 \mathrm{~m}$ to $\mathrm{ZC} 0+163 \mathrm{~m}$, and the crack extended along $\mathrm{C}_{2}$, as shown in Figure 13(d). After the excavation of the powerhouse, the crack reached a total length of $78 \mathrm{~m}$ and was $0.3 \sim 2.0 \mathrm{~m}$ wide. Similar to the Jinping I underground powerhouse, the Baihetan left bank underground powerhouse was also affected by structural planes, which leads to large deformation of the local surrounding rock mass. Several gently dipping internal staggered zones, including $\mathrm{LS}_{3152}$, $\mathrm{LS}_{3253} \sim \mathrm{LS}_{3256}$, were above the arch of the powerhouse at the $1^{\#} \sim 4^{\#}$ unit, which compromised the integrity of the surrounding rock mass. As a consequence, the surrounding rock mass of this area had larger deformation than that at the $5^{\#} \sim 8^{\#}$ unit during excavation.

Apart from the fracture structure mentioned above, the attitude of strata sometimes influences powerhouse stability as well. A strike perpendicular to the powerhouse axis is beneficial to the stability of the surrounding rock mass, particularly to the stability of the sidewall. However, if the strike of strata is parallel to the powerhouse axis and the strata are thin and poorly connected, roof collapse would occur, especially for the powerhouse with a large span. Hence, in the case of horizontal strata, the powerhouse should be located in homogeneous, thick, and hard strata.

Some properties of the rock mass, which have an impact on the stability of underground openings, can be used as the basis for assessment and classification of the surrounding 


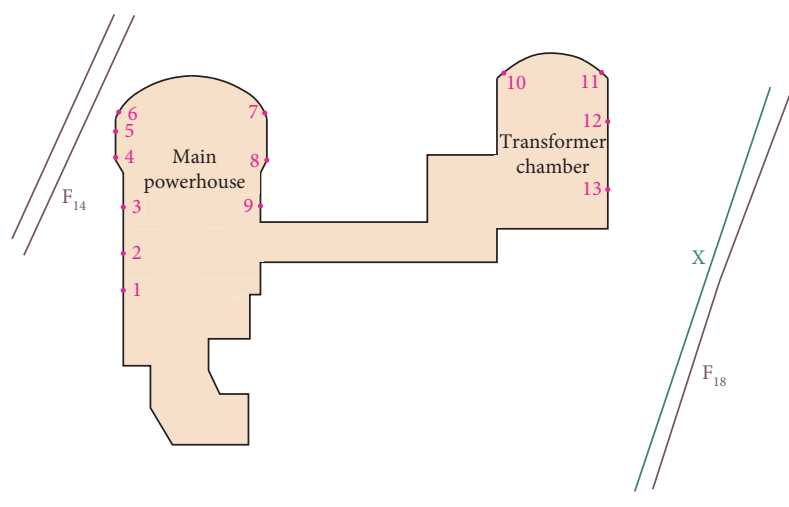

(a)

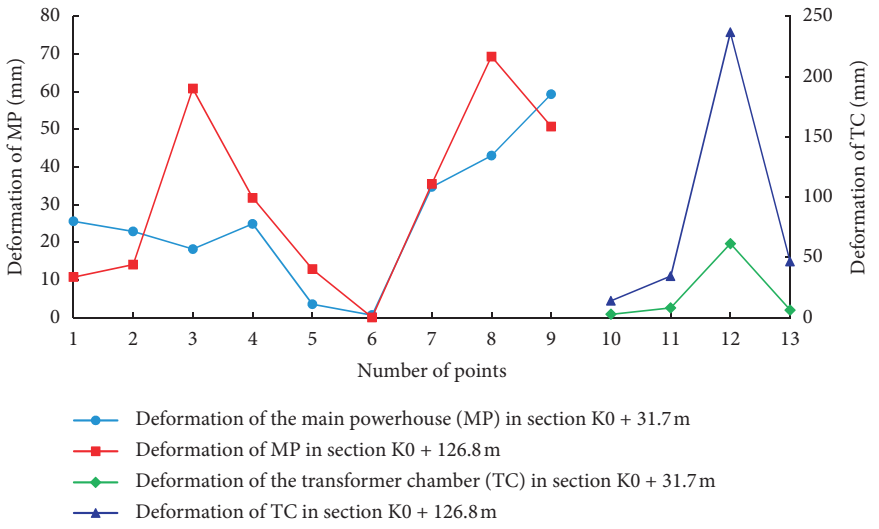

(b)

FIGURE 12: (a) Thirteen points for measuring surrounding rock mass deformation after excavation in both section $\mathrm{K} 0+31.7 \mathrm{~m}$ and section $\mathrm{K} 0+126.8 \mathrm{~m}$ and (b) the measurement results.

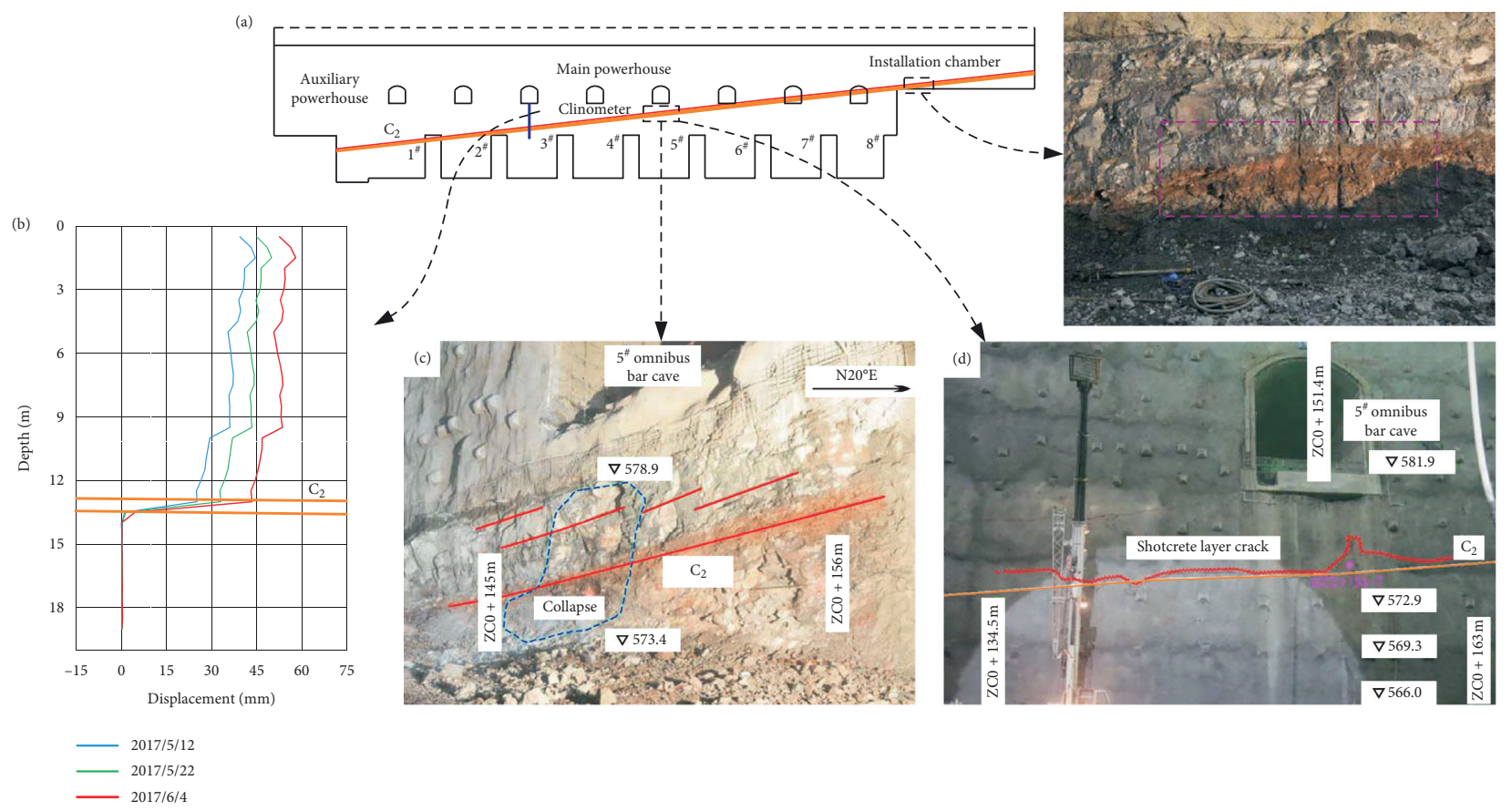

Figure 13: (a) Weak interlayer zone $\mathrm{C}_{2}$ at the Baihetan underground powerhouse and deformation and failures it caused: (b) shear deformation measured by the clinometer at the $3^{\#}$ omnibus bar cave, (c) local collapse, and (d) shotcrete layer crack.

rock mass and are prevalent methods to judge surrounding rock mass stability and guide construction and supporting design. The $Q$ system method [40] and RMR method [41] are two internationally common means of the rock mass classification. The former covers six parameters: rock quality designation (RQD), the number of joint sets, joint roughness, joint alteration, rock load, and water pressure. The latter includes rock compressive strength, RQD, joint spacing, joint state, groundwater state, and joint direction.

\section{Construction Factors}

Excavation of the underground powerhouse is the prerequisite for the deformation and failure of the surrounding rock mass. Rock mass remains in a state of complicated initial stress equilibrium prior to excavation. Excavation alters the initial geometry of the rock mass, and stress constraints of the excavated rock mass on the remaining are unloaded at the excavation face. By unloading, stress is adjusted and redistributed, facilitating the initiation and propagation of cracks in the surrounding rock mass. These cracks could significantly influence the strength and deformation behavior of the surrounding rock mass, thereby creating conditions for deformation and failure [42]. Except for excavation, the rock mass would stay in the equilibrium state, and the likelihood of deformation and failure would be low. Support, which belongs to the construction process together with excavation, plays a pivotal role in preventing 
and arresting deformation and failure of the surrounding rock mass.

Considering displacement measured by a multipoint extensometer, the impacts of excavation disturbance on the deformation of the surrounding rock mass can be demonstrated. To this end, the monitoring result of the multipoint extensometer that reported a large deformation magnitude is selected for analysis; $\mathrm{M}_{\mathrm{ZC}} 0+077-2$ is located on the upstream sidewall of the Baihetan main powerhouse at an elevation of $592.002 \mathrm{~m}$ and has an orifice displacement that exceeds $50 \mathrm{~mm}$. The blue curve in Figure 14(a) is the orifice displacement, and the red one is the displacement rate. As is reflected, the displacement has step growth, and the rate curve has a peak at every beginning of the excavation at the same elevation, illustrating that the deformation is strongly linked to the excavation process and that excavation disturbance at each elevation can make the surrounding rock mass deformation increase. When the excavation at an elevation of $591.96 \mathrm{~m}$ started, the displacement rate reached the maximum of the entire monitoring phase, $1.14 \mathrm{~mm} / \mathrm{d}$ (August 24, 2016), because at that time, the excavation face was closest to the measured point vertically. As excavation progresses, the excavation face moves away, and these peaks generally present a reduction tendency; this tendency indicates that, with the vertical distance between the measured point and the excavation face enlarging, the influences of excavation disturbance on the surrounding rock mass deformation fade away, and the deformation rate diminishes. On November 21, 2016, excavation from stake ZC0 $+70 \mathrm{~m}$ to $\mathrm{ZC} 0+85 \mathrm{~m}$ at elevation $583.9 \mathrm{~m}$ was in progress. The excavation face was close to the measured point horizontally, and thus, the displacement rate reached a maximum of $0.96 \mathrm{~mm} / \mathrm{d}$. The horizontal and vertical distance between the measured point and the excavation face, therefore, turn out to be closely related to the surrounding rock mass deformation at the measured point. As the distance increases, the effects of excavation disturbance on surrounding rock mass deformation are moderate, and the deformation rate dwindles.

Large underground powerhouse is featured by big size, complex structure, and long construction period; thus, the range of stress adjustment is wide, and the time is long. Large-scale stress adjustment makes greater impact on the surrounding rock mass and is likely to cause extensive failure, such as the long shotcrete cracks on the arch of the Baihetan left bank underground powerhouse. And in some cases, it may influence the adjacent caverns and lead to surrounding rock mass failures. Long-lasting stress adjustment may cause the deformation and failure of the surrounding rock mass to develop over time and even deteriorate. When the excavation is completed, failures usually stop developing. Thus, a reasonable excavation design based on the structural property of the powerhouse and geological conditions is vital to curbing deformation and minimizing failure of the surrounding rock mass. Optimal construction techniques, such as refined blasting techniques, that can control the undesirable effect of the blasting vibration on the surrounding rock mass also play an important part $[16,43-45]$. Moreover, the construction of large underground powerhouses featuring complex structures and intersecting caverns experiences interaction between adjacent or intersecting caverns and a complex process of stress adjustment. And it is worth for further research, in combination with engineering practice, to design reasonable construction procedures for adjacent and intersecting caverns so as to mitigate adverse impacts on the safety and stability of the underground powerhouse.

Support is a key factor in preventing the deformation and failure of the surrounding rock mass. Generally, the rock mass surrounding large-scale underground powerhouses is reinforced with anchor bolts, shotcrete, and prestressed anchor cables. With anchor bolts anchored in the rock mass, a common bearing body is formed via the combination of anchor bolts and rock mass, which can improve the strength of the rock mass and the shear resistance of the structural surface, thus reinforcing the surrounding rock mass. Prestressed anchor cables can moderate the negative effects of unloading induced by excavation on powerhouse stability and reduce surrounding rock mass deformation [46, 47]. Figure 14(b) shows the displacement curve of $\mathrm{M}_{\mathrm{ZC}} 0+229-2$ on the upstream sidewall of the Baihetan main powerhouse and the stress curve of its anchor bolts. As is reflected, the displacement and stress demonstrate step growth, and they share a similar response to excavation disturbance. The anchor bolt limits the surrounding rock mass deformation to the free surface, and the step-growing displacement makes the stress present a stage evolution process. As the excavation face moves away, the growth of displacement slows down, as does the growth of stress. Eventually, the displacement and stress tend to converge under the function of the supporting system. The displacement at a depth of $1.5 \mathrm{~m}$ is controlled below $50 \mathrm{~mm}$, which prevents large deformation of the surrounding rock mass. Thus, the effect of anchor bolts on limiting the surrounding rock mass deformation is obvious. Along the hole depth, the displacement as well as the stress decreases with the increase of depth.

On the contrary, belated or inappropriate support is sometimes responsible for the deformation and failure of the surrounding rock mass. During the excavation of the Baihetan underground powerhouse, surrounding rock mass at the upstream spandrel and downstream sidewall cracked. Unfortunately, local cracked rock mass remained unreinforced for a long time, and damage and cracks extended gradually. Ultimately, rockfall and collapse occurred in these areas.

\section{Discussion}

Through the analysis of recent large underground powerhouse cases, powerhouse layout and structure, rock mass properties, in situ stress, and construction factors are key factors affecting the deformation and failure of the surrounding rock mass. Among these factors, the two most fundamental factors are in situ stress and rock mass properties as these two remain unalterable for a determined powerhouse site, and their impacts can only be changed indirectly via adjusting other pertinent factors. Furthermore, in hydropower resource-rich southwest China that features 


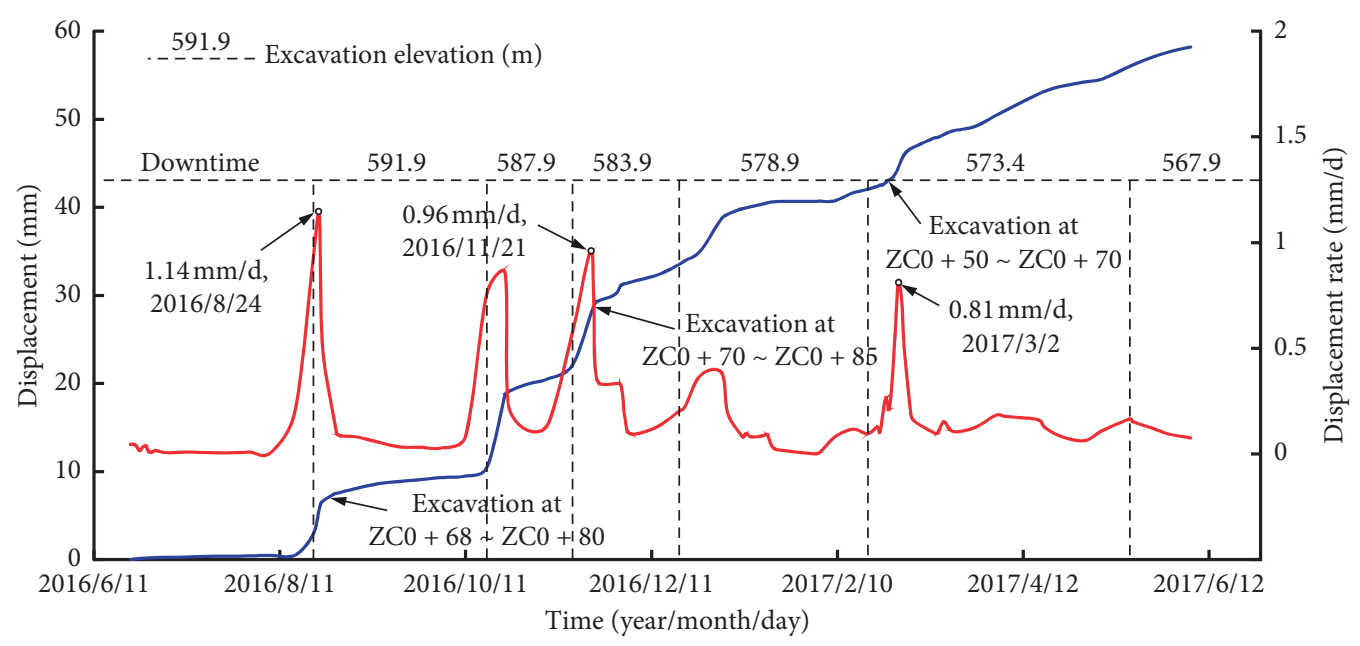

- Displacement
— Displacement rate

(a)

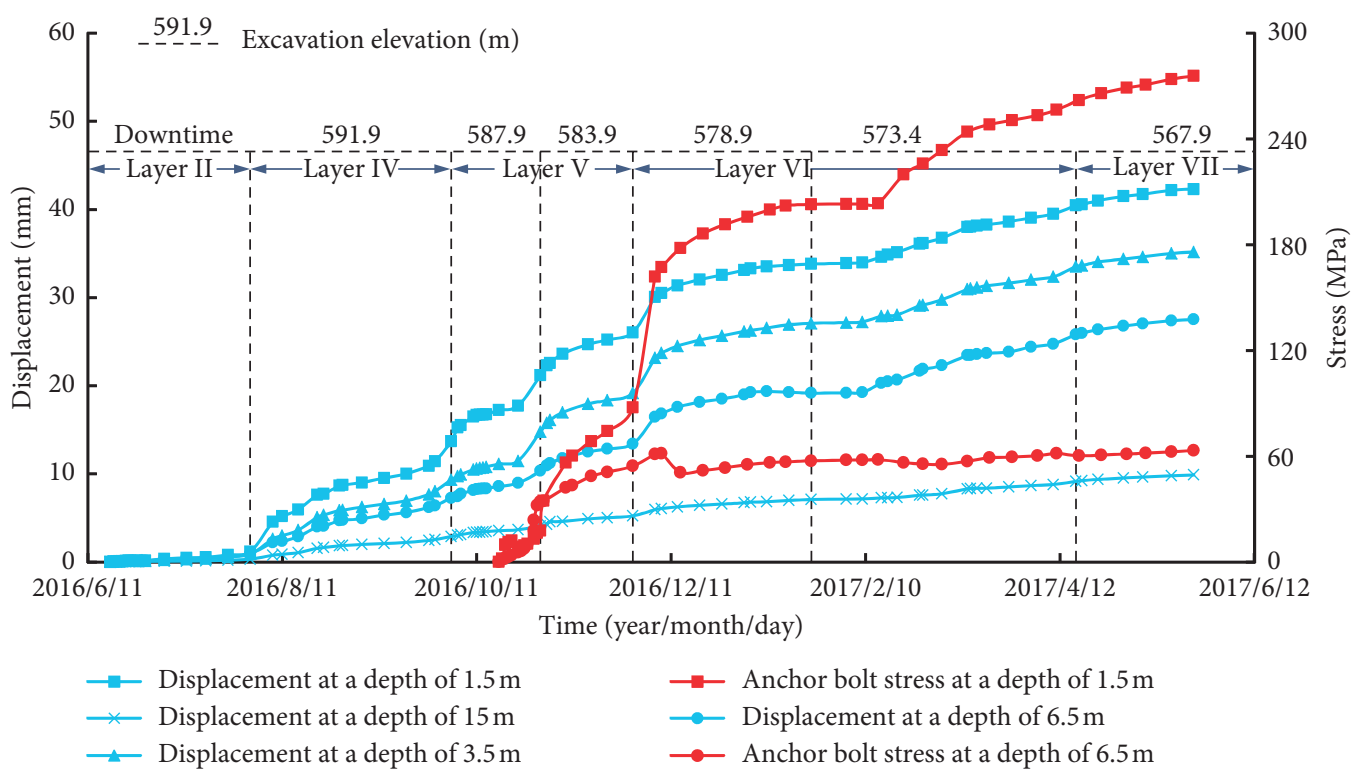

(b)

FIgURE 14: Monitoring result of the multipoint extensometer and anchor bolt: (a) displacement and displacement rate curves at stake $\mathrm{ZC} 0+77 \mathrm{~m}$; (b) displacement and anchor bolt stress curves at stake ZC0 $+229 \mathrm{~m}$.

complex geological conditions and high in situ stress, these two factors pose tremendous impacts on the deformation and failure of the surrounding rock mass.

As typical underground powerhouses under high in situ stress, Jinping I, Houziyan, and Baihetan experienced many stress-dominated failures of the surrounding rock mass during construction. Spalling, splitting, and large unloading deformation of the surrounding rock mass and cracking of the shotcrete layer were common issues of the three powerhouses, which were mainly caused by stress concentration after excavation. These failures accounted for a large proportion, indicating that the high in situ stress had a remarkable impact on the deformation and failure of the surrounding rock mass. On the contrary, the characteristic and mechanism of in situ stress among these three projects were quite different. The maximum principal stress in Baihetan had a large intersection angle with the powerhouse axis, and as a result, stress concentrated remarkably at the upstream side of the arch. Though the maximum principal stress intersected with the powerhouse axis at a small angle, the high second principal stress was subvertical to the axis, which played a dominant role in many surrounding rock mass failures. In spite of the similarly small angle between the maximum principal stress and the powerhouse axis, the relatively low rock mass strength under extremely high in situ stress provided a prerequisite for failures in the Jinping I underground powerhouse. In general, surrounding rock mass failures induced by high in situ stress have become a 
common key issue in the construction of large underground powerhouses.

Due to the complexity of the geological environment, some failures occurred in these three powerhouses which were induced by complex rock mass structure or adverse geological structures, such as collapse, block sliding, cracking, and shear deformation. These failures were not only rock mass property-dominated type but also rock mass property-stress-dominated type. Each project had a unique topographical and geological condition, and thus, the mode and extent of failure manifested difference among these powerhouses. For instance, unstable blocks and local collapse induced by structural planes' cutting and excavation disturbance were common problems in the three powerhouses. The deformation and failure caused by large-scale weak interlayer zone $\mathrm{C}_{2}$ in Baihetan, however, belonged to an individual problem.

Excavation of the underground powerhouse is the prerequisite of deformation and failure as it breaks the initial stress equilibrium state of the rock mass and disturbs the rock mass, thereby providing conditions for deformation and failure [48]. Underground powerhouse has a large scale and long construction period, and the stress adjustment caused by excavation is long-lasting. Thus, it has been a prevalent phenomenon that the deformation and failure of the surrounding rock mass develop with the excavation process. Support is an effective measure to curb the deformation and failure of the surrounding rock mass. Conversely, belated support is very likely to make failure develop, and under such circumstances, supplementary reinforcement is necessary. The construction of some underground powerhouses has encountered this problem, and relevant experience should be summarized based on typical cases. The layout and structure of the underground powerhouse also affect surrounding rock mass stability. The relationship between the powerhouse axis and the direction of in situ stress has an effect on the property of the redistributed stress field, and the relative position relationship between the powerhouse and detrimental geological structures exerts an influence on surrounding rock mass stability as well.

For specific project backgrounds, the importance and influence degree of these factors vary. Li et al. [49] determined the weight of each factor in underground powerhouse stability based on an analytic hierarchy process. This method can quantify the influence degree of factors, and if it is applied in multiple large-scale underground powerhouses and the results are summarized, a better understanding of key factors affecting the deformation and failure of the surrounding rock mass will be acquired.

In many cases, two or more factors come into play, not just one. The tension failure of the Houziyan main powerhouse mentioned in Section 4.2 results from two factors, in situ stress and rock mass structure. The effects of the powerhouse shape on stability were proven to be linked to both lateral stress and vertical stress ratios $(k)$, which are in situ stress field characteristics and to the rock property. For $0.2<k<2.2$, an elliptical shape shows the least displacement. When $k<0.2$, however, a mushroom shape is optimal in the surrounding rock mass with better quality, while a horseshoe shape is preferred for weak rock masses [50]. The failure risk of a surrounding rock mass with a weak interlayer zone is greatly affected by the shape and dimension, particularly by the span. The increased excavation span induces changes in the combination of the weak interlayer zone and the powerhouse, thereby triggering more massive collapses or contact shear slips [51]. The phenomenon of deformation of the upstream sidewall being greater than that of the downstream sidewall during the excavation of a large-scale underground powerhouse in high dipping laminar strata closely relates to the high-dip rock strata, joint arrays, and high horizontal in situ stress [52]. Deep fracturing of the surrounding rock mass is attributable to the combined effects of high in situ stress, enhanced stress concentration in deeper parts of the rock mass when excavated, and low strength of jointed surrounding rock mass [53]. As a result of the complexity of the geological environment, surrounding rock mass failures induced by high in situ stress and rock mass property jointly are common such as the surrounding rock mass fracture and block sliding at the downstream sidewall of the Houziyan underground powerhouse, the splitting failure along bedding fissures in the stress concentration zone at the downstream sidewall foot, and the shear deformation of the weak interlayer zone caused by unloading in the Baihetan underground powerhouse. Rock mass property-stress-dominated failure took place in many projects and showed various failure modes and mechanisms. Besides, it can be seen that factors are interrelated and influence each other, and the combined impact is likely to be more pronounced or severe than that of a single factor, for example, the rock mass splitting failure in the stress concentration zone at the downstream sidewall foot of the Baihetan underground powerhouse. In this stress concentration zone, the high maximum principal stress approximately parallel to the rock mass bedding made bedding fissures open and grow, and eventually, it caused the surrounding rock mass to split. The main factors of this failure are the high redistributed stress and bedding fissures. The former is trigger, and the latter is precondition with respect to the rock mass property. Without either factor, the failure would not have occurred. Hence, it is of necessity to study the synergistic mechanism of multiple factors and put forward measures for each factor.

\section{Conclusions}

Through the analysis of the cause and mechanism of deformation and failure in typical cases, this paper provides an overview of key factors affecting the deformation and failure of the rock mass surrounding large-scale underground powerhouses in hydropower stations, including the layout and structure of the powerhouse, in situ stress, rock mass properties, and construction factors. In situ stress and rock mass properties, on account of their immutability and dramatic impacts demonstrated in a large number of cases, are the two most fundamental factors of all the considered factors. The layout and structure of the powerhouse, as well as construction factors, are also significant. Essentially, the selection of the powerhouse location and direction indirectly 
alters impacts of the rock mass properties and in situ stress on surrounding rock mass stability. The construction process consists of two major events, excavation and supporting. The former is the prerequisite to surrounding rock mass failure, and the latter is the key to prevent and arrest the deformation and failure of the surrounding rock mass. In many cases, two or more factors come into play, not just one, and these factors are also interrelated and influence each other.

Affected by the unique topographical and geological condition in southwest China, the construction of many large-scale underground powerhouses has encountered failure issues caused by high in situ stress or rock mass property, or both. Thus, the countermeasures for these factors in design and construction are critical to the surrounding rock mass stability. In the design stage, the impact of these adverse factors on surrounding rock mass stability should be avoided or mitigated through optimized design based on the experience and theory from similar projects. Comprehensive assessment on the impact is indispensable when making a reasonable support design, and avoiding supplementary reinforcement is implemented repeatedly. During the construction period, the construction method for large-scale underground powerhouses under high in situ stress and complex geological environment, together with the multisource safety monitoring system for the surrounding rock mass, should be adopted. The former covers novel excavation methods for the long-span arch, high sidewall, and intersecting chambers, support fast follow-up excavation technology, and reinforcement measures for unfavorable geology, through which excavation damage can be alleviated, and surrounding rock mass deformation can be curbed within a reasonable range. The latter includes conventional monitoring for surrounding rock deformation, anchor cable load and bolt stress, acoustic test, and advanced monitoring technology, by which the stability evaluation for the surrounding rock mass, safety warning for the cavern group, and dynamic control for deformation and failures can be realized. In this way, the key problem of deformation and failure can be overcome, and the construction safety and efficiency can be guaranteed.

\section{Data Availability}

The data used to support the findings of this study are included within the article.

\section{Conflicts of Interest}

The authors declare that there are no conflicts of interest regarding this publication.

\section{Acknowledgments}

The authors gratefully acknowledge the support of the Graduate Student's Research Innovation Foundation of Sichuan University (2018YJSY076) and the Science Foundation for Excellent Youth Scholars of Sichuan University (2013SCU04A07).

\section{References}

[1] H. B. Li, M. C. Liu, W. B. Xing, S. Shao, and J. W. Zhou, "Failure mechanisms and evolution assessment of the excavation damaged zones in a large-scale and deeply buried underground powerhouse," Rock Mechanics and Rock Engineering, vol. 50, no. 1, pp. 1883-1900, 2017.

[2] X.-h. Xiao, P.-w. Xiao, F. Dai, H.-b. Li, X.-b. Zhang, and J.-w. Zhou, "Large deformation characteristics and reinforcement measures for a rock pillar in the Houziyan underground powerhouse," Rock Mechanics and Rock Engineering, vol. 51, no. 2, pp. 561-578, 2017.

[3] F. Dai, B. Li, N. Xu, Y. Fan, and C. Zhang, "Deformation forecasting and stability analysis of large-scale underground powerhouse caverns from microseismic monitoring," International Journal of Rock Mechanics and Mining Sciences, vol. 86, pp. 269-281, 2016.

[4] F. Chen, C. He, and J. H. Deng, "Concept of high geostress and its qualitative and quantitative definitions," Rock and Soil Mechanics, vol. 36, no. 4, pp. 971-980, 2015, in Chinese.

[5] Y. Li, H. Wang, W. Zhu, S. Li, and J. Liu, "Structural stability monitoring of a physical model test on an underground cavern group during deep excavations using FBG sensors," Sensors, vol. 15, no. 9, pp. 21696-21709, 2015.

[6] Y. J. Shen, G. L. Xu, and J. N. Yi, "A systematic engineering geological evaluation of diabase dikes exposed at the underground caverns of Dagangshan hydropower station, Southwest China," Environmental Earth Sciences, vol. 76, no. 14, pp. 1-14, 2017.

[7] Y.-F. Chen, H.-K. Zheng, M. Wang, J.-M. Wang, and C.-B. Zhou, "Excavation-induced relaxation effects and hydraulic conductivity variations in the surrounding rocks of a large-scale underground powerhouse cavern system," Tunnelling and Underground Space Technology, vol. 49, pp. 253267, 2015.

[8] X.-P. Zhou, Y.-X. Zhang, Q.-L. Ha, and K.-S. Zhu, "Micromechanical modelling of the complete stress-strain relationship for crack weakened rock subjected to compressive loading," Rock Mechanics and Rock Engineering, vol. 41, no. 5, pp. 747-769, 2008.

[9] J. C. Zhang, W. Y. Xu, H. L. Wang, R. B. Wang, and Q. X. Meng, "Testing and modeling of the mechanical behavior of dolomite in the Wudongde hydropower plant," Geomechanics and Geoengineering, vol. 11, no. 4, pp. 270-280, 2016.

[10] W. Y. Xu, J. C. Zhang, W. Wang, and R. B. Wang, "Investigation into in situ stress fields in the asymmetric V-shaped river valley at the Wudongde dam site, southwest China," Bulletin of Engineering Geology and the Environment, vol. 73, no. 2, pp. 465-477, 2014.

[11] H.-b. Li, S.-c. Qi, X.-g. Yang, X.-w. Li, and J.-w. Zhou, "Geological survey and unstable rock block movement monitoring of a postearthquake high rock slope using terrestrial laser scanning," Rock Mechanics and Rock Engineering, 2020.

[12] G. J. Shao, J. S. Zhuo, and Q. Zhang, "Research on analysis method and criterion of rockmass stability," Chinese Journal of Rock Mechanics and Engineering, vol. 22, no. 5, pp. 691-696, 2003, in Chinese.

[13] J. W. Zhou, H. B. Li, and X. G. Yang, Deformation, Failure and Dynamic Response of Large Underground Powerhouse in Hydropower Engineering, Science Press, Beijing, China, 2020, in Chinese.

[14] J. C. Wu, Y. M. Zhang, and H. X. Li, "Stability analysis of underground caverns by jointed finite element method," Applied Mechanics and Materials, vol. 238, pp. 814-817, 2012. 
[15] N. Xu, F. Dai, B. Li, Y. Zhu, T. Zhao, and D. Yang, "Comprehensive evaluation of excavation-damaged zones in the deep underground caverns of the Houziyan hydropower station, Southwest China," Bulletin of Engineering Geology and the Environment, vol. 76, no. 1, pp. 275-293, 2017.

[16] Q. H. Qian and X. P. Zhou, "Failure behaviors and rock deformation during excavation of underground cavern group for Jinping I Hydropower Station," Rock Mechanics and Rock Engineering, vol. 51, no. 5, pp. 2639-2651, 2018.

[17] R. S. Read, "20 years of excavation response studies at AECL's Underground Research Laboratory," International Journal of Rock Mechanics and Mining Sciences, vol. 41, no. 8, pp. 1251-1275, 2004.

[18] R. Q. Huang, D. Huang, S. H. Duan, and Q. Wu, "Geomechanics mechanism and characteristics of surrounding rock mass deformation failure in construction phase for underground powerhouse of Jinping I Hydropower Station," Chinese Journal of Rock Mechanics and Engineering, vol. 30, no. 1, pp. 23-25, 2011, in Chinese.

[19] National Energy Administration of the People's Republic of China, Technical Code for Underground Project Geological Investigation of Hydropower and Water Resources, National Energy Administration of the People's Republic of China, Beijing, China, 2009, in Chinese.

[20] D. Fellner and D. Hobson, "HPP Glendoe - rock mechanical aspects for large span underground powerhouse," Geomechanik Und Tunnelbau, vol. 1, no. 5, pp. 374-381, 2008.

[21] Y. H. Zhang, Y. R. Lu, H. M. Zhou, and Z. W. Zhong, "Study of relationship between failure properties of surrounding rock and direction of geostress," Chinese Journal of Rock Mechanics and Engineering, vol. 29, no. S2, pp. 3526-3535, 2010, in Chinese.

[22] L. Li, J. D. He, T. Yu, and J. W. Fan, "Optimized design on the direction of longitudinal axle of underground plant," Journal of Sichuan University, vol. 35, no. 3, pp. 34-37, 2003, in Chinese.

[23] W. S. Zhu, B. Sui, X. J. Li, S. C. Li, and W. T. Wang, "A methodology for studying the high wall displacement of large scale underground cavern complexes and it's applications," Tunnelling and Underground Space Technology, vol. 23, no. 6, pp. 651-664, 2008.

[24] T. Mizukoshi and Y. Mimaki, "Deformation behaviour of a large underground cavern," Rock Mechanics and Rock Engineering, vol. 18, no. 4, pp. 227-251, 1985.

[25] X. X. Kong, Q. S. Liu, Q. B. Zhang, Y. X. Wu, and J. Zhao, “A method to estimate the pressure arch formation above underground excavation in rock mass," Tunnelling and Underground Space Technology, vol. 71, pp. 382-390, 2018.

[26] Ministry of Water Resources of the People's Republic of China, Specification for Design of Hydraulic Tunnel, Ministry of Water Resources of the People's Republic of China, 2016, in Chinese.

[27] D. Park, D.-W. Ryu, and B.-H. Choi, "Numerical analysisbased shape design of underground rock caverns for thermal energy storage," Rock Mechanics and Rock Engineering, vol. 47, no. 6, pp. 2307-2312, 2014.

[28] H. B. Liu and M. Xiao, "Stability assessment of surrounding rock of underground cavern complexes based on energydissipation model," in Proceedings of the 2010 Asia-Pacific Power and Energy Engineering Conference, pp. 1-4, Chengdu, China, March 2010.

[29] M. Wang, H.-b. Li, J.-q. Han, X.-h. Xiao, and J.-w. Zhou, "Large deformation evolution and failure mechanism analysis of the multi-freeface surrounding rock mass in the Baihetan underground powerhouse," Engineering Failure Analysis, vol. 100, pp. 214-226, 2019.

[30] M. Cai, P. K. Kaiser, Y. Tasaka, T. Maejima, H. Morioka, and M. Minami, "Generalized crack initiation and crack damage stress thresholds of brittle rock masses near underground excavations," International Journal of Rock Mechanics and Mining Sciences, vol. 41, no. 5, pp. 833-847, 2004.

[31] W. D. Ortlepp, "Observation of mining-induced faults in an intact rock mass at depth," International Journal of Rock Mechanics and Mining Sciences, vol. 37, no. 1-2, pp. 423-436, 2000.

[32] F. Q. Gong, W. X. Wu, T. B. Li, and X. F. Si, "Experimental simulation and investigation of spalling failure of rectangular tunnel under different three-dimensional stress states," International Journal of Rock Mechanics and Mining Sciences, vol. 122, Article ID 104081, 2019.

[33] Y. J. Shen, G. L. Xu, S. W. Song, Z. P. Li, X. M. Feng, and J. X. Dong, "A classification method of surrounding rock mass in hydropower project in high geostress area," Chinese Journal of Rock Mechanics and Engineering, vol. 33, no. 11, pp. 2267-2275, 2014, in Chinese.

[34] H.-b. Li, X.-g. Yang, X.-b. Zhang, and J.-w. Zhou, "Deformation and failure analyses of large underground caverns during construction of the Houziyan Hydropower station, Southwest China," Engineering Failure Analysis, vol. 80, pp. 164-185, 2017.

[35] ISRM, "Basic geotechnical description of rock masses," International Journal of Rock Mechanics and Mining Science and Geomechanics Abstracts, vol. 18, no. 1, pp. 85-110, 1981.

[36] J. Yu, G. Y. Liu, Y. Y. Cai, J. F. Zhou, S. Y. Liu, and B. X. Tu, "Time-dependent deformation mechanism for swelling softRock tunnels in coal mines and its mathematical deduction," International Journal of Geomechanics, vol. 20, no. 3, 2020.

[37] B. Wang, T. Li, C. He, and Y. Zhou, "Characteristics, causes and control measures of disasters for the soft-rock tunnels in the Wenchuan seismic regions," Journal of Geophysics and Engineering, vol. 13, no. 4, pp. 470-480, 2016.

[38] A. Wu, Q. Yang, X. Ding, and H. Zhou, "Key rock mechanical problems of underground powerhouse in Shuibuya hydropower station," Journal of Rock Mechanics and Geotechnical Engineering, vol. 3, no. 1, pp. 64-72, 2011.

[39] B. H. Lu, P. K. Kaiser, and G. Grasselli, "Influence of persistence on behaviour of fractured rock masses," Geological Society, London, Special Publications, vol. 284, no. 1, pp. 161-173, 2007.

[40] N. Barton, R. Lien, and J. Lunde, "Engineering classification of rock masses for the design of tunnel support," Rock Mechanics Felsmechanik Mecanique des Roches, vol. 6, no. 4, pp. 189-236, 1974.

[41] Z. T. Bieniawski, "Engineering rock mass classification," Petroleum, vol. 251, no. 3, pp. 357-365, 1989.

[42] Y. Jiang, B. Li, and Y. Yamashita, "Simulation of cracking near a large underground cavern in a discontinuous rock mass using the expanded distinct element method," International Journal of Rock Mechanics and Mining Sciences, vol. 46, no. 1, pp. 97-106, 2009.

[43] T. Szwedzicki, "Rock mass behaviour prior to failure," International Journal of Rock Mechanics and Mining Sciences, vol. 40, no. 4, pp. 573-584, 2003.

[44] J. P. Zuo, Z. D. Li, S. K. Zhao, Y. Q. Jiang, H. Y. Liu, and M. H. Yao, "A study of fractal deep-hole blasting and its induced stress behavior of hard roof strata in Bayangaole coal mine, China," Advances in Civil Engineering, vol. 2019, Article ID 9504101, 14 pages, 2019. 
[45] C. Bedon, C. Amadio, L. Chen, V. Matsagar, F. Wellershoff, and X. H. Zhang, "Advancements in design, analysis, and retrofitting of structures exposed to blast," Advances in Civil Engineering, vol. 2016, Article ID 1345478, 2 pages, 2016.

[46] H. H. Zhu, M. C. Chen, Y. Zhao, and F. S. Niu, "Key techniques of underground engineering stable equilibrium theory," in Stability Assessment for Underground Excavations and Key Construction Techniques, pp. 33-92, Springer, Berlin, Germany, 2017.

[47] Z. Huang, E. Broch, and M. Lu, "Cavern roof stabilitymechanism of arching and stabilization by rockbolting," Tunnelling and Underground Space Technology, vol. 17, no. 3, pp. 249-261, 2002.

[48] K. Bian and M. Xiao, "Research on optimization method for underground cavern excavation," in Proceedings of the International Conference on Intelligent Computation Technology and Automation, pp. 269-272, Changsha, China, October 2009.

[49] X. J. Li, W. S. Zhu, W. Z. Chen, and K. Wu, "Determining weight of factors in stability analysis of underground caverns by analytic hierarchy process," Chinese Journal of Rock Mechanics and Engineering, vol. 23, no. S2, pp. 4731-4734, 2004, in Chinese.

[50] A. Abdollahipour and R. Rahmannejad, "Investigating the effects of lateral stress to vertical stress ratios and caverns shape on the cavern stability and sidewall displacements," Arabian Journal of Geosciences, vol. 6, no. 12, pp. 4811-4819, 2013.

[51] S.-Q. Duan, X.-T. Feng, Q. Jiang, G.-F. Liu, S.-F. Pei, and Y.-L. Fan, "In situ observation of failure mechanisms controlled by rock masses with weak interlayer zones in large underground cavern excavations under high geostress," Rock Mechanics and Rock Engineering, vol. 50, no. 9, pp. 24652493, 2017.

[52] W. Z. Chen, S. C. Li, W. S. Zhu, D. S. Yang, and W. M. Yang, "Excavation and optimization theory for giant underground multiple openings in high dipping laminar strata," Tunnelling and Underground Space Technology, vol. 19, no. 4, pp. 435-436, 2004.

[53] X.-T. Feng, S.-F. Pei, Q. Jiang, Y.-Y. Zhou, S.-J. Li, and Z.-B. Yao, "Deep fracturing of the hard rock surrounding a large underground cavern subjected to high geostress: in situ observation and mechanism analysis," Rock Mechanics and Rock Engineering, vol. 50, no. 8, pp. 2155-2175, 2017. 